\title{
$\mathrm{J}$

\section{Photoacidic and Photobasic Behavior of Transition Metal Compounds with Carboxylic Acid Group(s)}

Ryan M. O’Donnell, Renato N. Sampaio, Guocan Li, Patrik G. Johansson, Cassandra L. Ward, and Gerald J. Meyer*

Department of Chemistry, University of North Carolina at Chapel Hill, Chapel Hill, North Carolina 27599, United States

\section{Supporting Information}

ABSTRACT: Excited state proton transfer studies of six Ru polypyridyl compounds with carboxylic acid/carboxylate group(s) revealed that some were photoacids and some were photobases. The compounds $\left[\mathrm{Ru}^{\mathrm{II}}(\mathrm{btfmb})_{2}(\mathrm{LL})\right]^{2+}$, $\left[\mathrm{Ru}^{\mathrm{II}}(\mathrm{dtb})_{2}(\mathrm{LL})\right]^{2+}$, and $\left[\mathrm{Ru}^{\mathrm{II}}(\mathrm{bpy})_{2}(\mathrm{LL})\right]^{2+}$, where bpy is $2,2^{\prime}$-bipyridine, btfmb is $4,4^{\prime}-\left(\mathrm{CF}_{3}\right)_{2}$-bpy, and dtb is $4,4^{\prime}$ $\left(\left(\mathrm{CH}_{3}\right)_{3} \mathrm{C}\right)_{2}$-bpy, and $\mathrm{LL}$ is either dcb $=4,4^{\prime}-\left(\mathrm{CO}_{2} \mathrm{H}\right)_{2}$-bpy or $\mathrm{mcb}=4-\left(\mathrm{CO}_{2} \mathrm{H}\right), 4^{\prime}-\left(\mathrm{CO}_{2} \mathrm{Et}\right)-2,2^{\prime}$-bpy, were synthesized and characterized. The compounds exhibited intense metal-toligand charge-transfer (MLCT) absorption bands in the visible region and room temperature photoluminescence (PL) with long $\tau>100 \mathrm{~ns}$ excited state lifetimes. The mcb compounds had very similar ground state $\mathrm{p} K_{\mathrm{a}}$ 's of $2.31 \pm 0.07$, and their

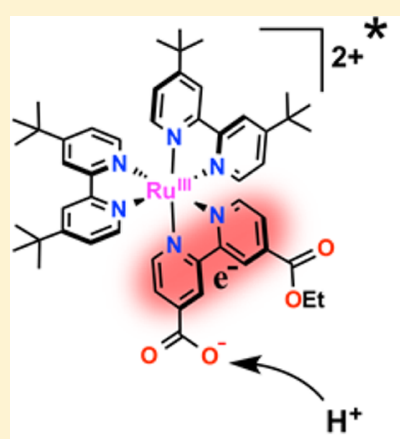

Photo-base

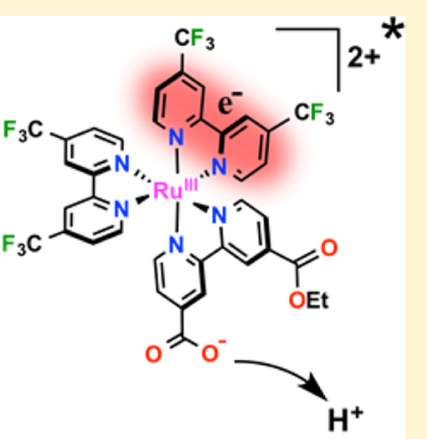

Photo-acid characterization enabled accurate determination of the two $\mathrm{p} K_{\mathrm{a}}$ values for the commonly utilized dcb ligand, $\mathrm{p} K_{\mathrm{a} 1}=2.1 \pm 0.1$ and $\mathrm{p} K_{\mathrm{a} 2}=3.0 \pm 0.2$. Compounds with the btfmb ligand were photoacidic, and the other compounds were photobasic. Transient absorption spectra indicated that btfmb compounds displayed a $\left[\mathrm{Ru}^{\mathrm{III}}\left(\mathrm{btfmb}^{-}\right) \mathrm{L}_{2}\right]^{2+*}$ localized excited state and a $\left[\mathrm{Ru}^{\mathrm{III}}\left(\mathrm{dcb}^{-}\right) \mathrm{L}_{2}\right]^{2+*}$ formulation for all the other excited states. Time dependent PL spectral shifts provided the first kinetic data for excited state proton transfer in a transition metal compound. PL titrations, thermochemical cycles, and kinetic analysis (for the mcb compounds) provided self-consistent $\mathrm{pK}_{\mathrm{a}}^{*}$ values. The ability to make a single ionizable group photobasic or photoacidic through ligand design was unprecedented and was understood based on the orientation of the lowest-lying MLCT excited state dipole relative to the ligand that contained the carboxylic acid group(s).

\section{INTRODUCTION}

Chromophores with Brønsted acidic or basic functional groups often exhibit excited-state acid-base behavior that differs significantly from that of the ground state. ${ }^{1,2}$ Weber first observed such behavior back in 1931, and studies since have exploited this behavior for application as $\mathrm{pH}$ sensors, ${ }^{3-5}$ photopolymerization, ${ }^{6-8}$ synthesis, ${ }^{9}$ solar-fuel production, ${ }^{10}$ biological probes, ${ }^{11-14}$ molecular switches, ${ }^{15,16}$ as well as for fundamental studies of proton transfer and/or proton coupled electron transfer (PCET) reactions ${ }^{17-19}$ as has been the subject of several reviews. ${ }^{20-24}$ This chemistry is understood though the very familiar acid-base equilibrium which in this case is between a carboxylic acid $\mathrm{R}\left(\mathrm{CO}_{2} \mathrm{H}\right)$, and its conjugate carboxylate $\mathrm{R}\left(\mathrm{CO}_{2}{ }^{-}\right)$, defined by an equilibrium constant, $K_{a}$, eq 1 . Light absorption by the acid form generates an excited state, $\mathrm{HA}^{*}$, that may release a proton to a greater extent than the ground state and hence is termed a photoacid, eq 2 .

$$
\begin{aligned}
& \mathrm{R}\left(\mathrm{CO}_{2} \mathrm{H}\right) \stackrel{\mathrm{K}_{\mathrm{a}}}{\rightleftharpoons} \mathrm{R}\left(\mathrm{CO}_{2}^{-}\right)+\mathrm{H}^{+} \\
& \mathrm{R}\left(\mathrm{CO}_{2} \mathrm{H}\right) * \stackrel{K_{\mathrm{a}}^{*}}{\rightleftharpoons} \mathrm{R}\left(\mathrm{CO}_{2}^{-}\right)^{*}+\mathrm{H}^{+}
\end{aligned}
$$

Likewise, light absorption by the conjugate base $\mathrm{R}\left(\mathrm{CO}_{2}{ }^{-}\right)$ forms $\mathrm{R}\left(\mathrm{CO}_{2}^{-}\right)^{*}$ that may accept a proton and acts as a photobase. Under steady state illumination, a quasi-equilibrium defined by $K_{\mathrm{a}}^{*}$ can be achieved wherein the solution concentrations remain invariant with time. The net change in acid-base chemistry with illumination is often quantified by the magnitude of $\Delta \mathrm{p} K_{\mathrm{a}}=\mathrm{p} K_{\mathrm{a}}{ }^{*}-\mathrm{p} K_{\mathrm{a}}{ }^{1,22}$ It is quite usual to find that the acid dissociation constant of the protonated forms of the compounds change by $4-10 \mathrm{p} K_{\mathrm{a}}$ units upon light absorption. Here we report $\mathrm{p} K_{\mathrm{a}}$ and $\mathrm{p} K_{\mathrm{a}}{ }^{*}$ values, as well as the first excited state proton transfer rate constants, for a series of six $\mathrm{Ru}(\mathrm{II})$ polypyridyl compounds with one or two pendant carboxylic acid groups.

The increased basicity or acidity of an excited state reflects the redistribution of electron density that results from photon absorption and is of fundamental interest in its own right. ${ }^{1,2}$ Reviews of excited-state acid-base chemistry teach that the identity of the ionizable functional group dictates whether light excitation will produce a photoacid or a photobase without regard to the nature of the excited state. ${ }^{1,2,22,25}$ For example, phenols are

Received: January 20, 2016

Published: February 22, 2016 


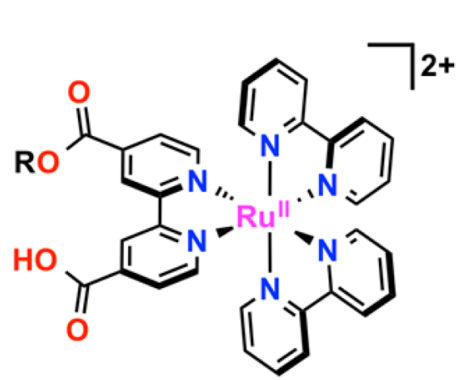

$\left[\mathrm{Ru}(\mathrm{bpy})_{2}(\mathrm{mcb})\right]^{2+} \quad\left(\mathrm{R}=\mathrm{CH}_{2} \mathrm{CH}_{3}\right)$

$\left[\mathrm{Ru}(\mathrm{bpy})_{2}(\mathrm{dcb})\right]^{2+} \quad(\mathrm{R}=\mathbf{H})$

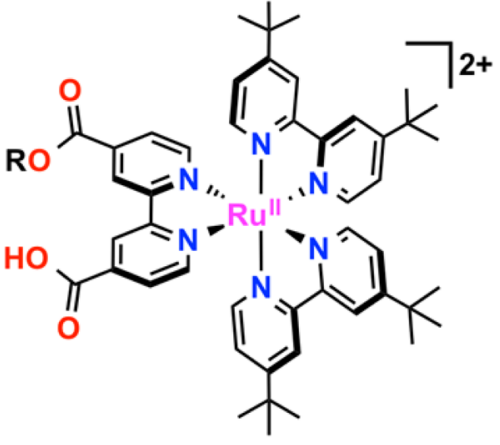

$\left[\mathrm{Ru}(\mathrm{dtb})_{2}(\mathrm{mcb})\right]^{2+} \quad\left(\mathrm{R}=\mathrm{CH}_{2} \mathrm{CH}_{3}\right)$

$\left[\mathrm{Ru}(\mathrm{dtb})_{2}(\mathrm{dcb})\right]^{2+} \quad(\mathrm{R}=\mathrm{H})$

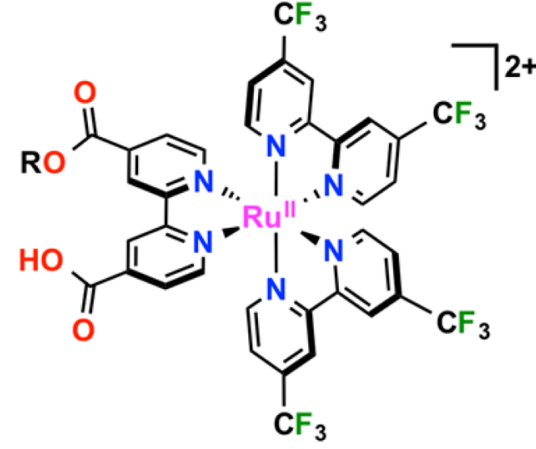

$\left[\mathrm{Ru}(\mathrm{btfmb})_{2}(\mathrm{mcb})\right]^{2+} \quad\left(\mathrm{R}=\mathrm{CH}_{2} \mathrm{CH}_{3}\right)$

$\left[\mathrm{Ru}(\mathrm{btfmb})_{2}(\mathrm{dcb})\right]^{2+} \quad(\mathrm{R}=\mathrm{H})$

Figure 1. Ruthenium polypyridyl compounds investigated herein.

always more acidic in the excited state than the ground state. Likewise, carboxylates are always more basic in their excited states. In other words, whether the acid ionization constant increases or decreases upon light absorption has always been solely determined by the identity of the functional group. Here we report the first exception to this rule. Carboxylic acid/ carboxylate functional groups with almost identical ground state $\mathrm{p} K_{\mathrm{a}}$ values can be made more acidic or more basic than the ground state in $\mathrm{Ru}(\mathrm{II})$ polypyridyl compounds.

Many literature reports of excited state acid-base chemistry in transition metal compounds have appeared since the first reports by Demas and Peterson ${ }^{26}$ in $1976 .{ }^{1,2,27-47}$ All known ruthenium polypyridine compounds with pendant carboxylates ${ }^{30-34}$ or amines ${ }^{35-37}$ were found to be photobases. Photoacidic ruthenium compounds are relatively rare and until now appear to be limited to phenol-type ${ }^{28}$ or ambidentate cyanide ligands. ${ }^{38}$ Most relevant to this manuscript are the studies of $[\mathrm{Ru}-$ $\left.(\mathrm{bpy})_{2}(\mathrm{dcb})\right]^{2+},{ }^{27}$ which is a weaker acid in the excited state than in the ground state, that is, a photobase. The presence of two carboxylic acid groups in $\left[\mathrm{Ru}(\mathrm{bpy})_{2}(\mathrm{dcb})\right]^{2+}$ and the very similar absorption spectra of the mono- and diprotonated forms of this compound has led to significant discrepancy in the reported ionization constants. ${ }^{27,32,33,48,49}$ This is unfortunate as the $\mathrm{dcb}$ ligand is commonly utilized for solar energy applications, such as in dye-sensitized solar cells. ${ }^{50-52}$ The syntheses of model compounds and full wavelength spectral analysis reported herein have enabled accurate determination of the equilibrium constants and insights into their acid-base behavior.

The six ruthenium polypyridyl chromophores, presented in Figure 1, containing carboxylic acid substituted bipyridine ligands $\left[\mathrm{Ru}^{\mathrm{II}}(\mathrm{btfmb})_{2}(\mathrm{LL})\right]^{2+},\left[\mathrm{Ru}^{\mathrm{II}}(\mathrm{dtb})_{2}(\mathrm{LL})\right]^{2+}$, and $\left[\mathrm{Ru}^{\mathrm{II}}(\mathrm{bpy})_{2}(\mathrm{LL})\right]^{2+}$, where bpy is $2,2^{\prime}$-bipyridine, btfmb is $4,4^{\prime}$ $\left(\mathrm{CF}_{3}\right)_{2}$-bpy, and $\mathrm{dtb}$ is $4,4^{\prime}-\left(\left(\mathrm{CH}_{3}\right)_{3} \mathrm{C}\right)_{2}$-bpy, and $\mathrm{LL}$ is either $\mathrm{dcb}$ or $\mathrm{mcb}=4-\left(\mathrm{CO}_{2} \mathrm{H}\right), 4^{\prime}-\left(\mathrm{CO}_{2} \mathrm{Et}\right)-2,2^{\prime}$-bpy, were synthesized. All the compounds were similar ground state $\mathrm{p} K_{\mathrm{a}}$ values; however, the btfmb compounds were found to be photoacids that rapidly equilibrate in the excited state; the other compounds were photobases that undergo excited state proton transfer equilibria on the nanosecond time scale as was quantified through time dependent photoluminescence spectral shifts and kinetic modeling.

\section{EXPERIMENTAL SECTION}

Materials. The following reagents were used as received from the following commercial suppliers: acetonitrile (Burdick metric grad); ethanol and tert-butanol (Fisher, certified); tetrahydrofuran (THF,
Sigma-Aldrich, ACS grad); $\mathrm{RuCl}_{3} \cdot 3 \mathrm{H}_{2} \mathrm{O}$ (Pressure Chemical); argon gas (Airgas, >99.998\%); nitrogen gas (Airgas, 99.999\%). Hydrochloric acid $(\mathrm{HCl})$, ammonium hexafluorophosphate $\left(\mathrm{NH}_{4} \mathrm{PF}_{6}\right), n$-tetrabutylammonium hydroxide (TBAOH, 1.0 M in methanol), 4,4'-di-tert-butyl2,2'-bipyridine (dtb), $\mathrm{AgNO}_{3}, \mathrm{MgSO}_{4}$, palladium(II) acetate (Pd$\left.(\mathrm{OAc})_{2}\right), \mathrm{K}_{2} \mathrm{CO}_{3}, \mathrm{NaOH}, \mathrm{LiCl}, 2$-bromo-4-(trifluoromethyl)pyridine, tetrabutyl ammonium iodide (TBAI), and $\left[\mathrm{Ru}(\mathrm{bpy})_{3} \mathrm{Cl}_{2} \cdot 6 \mathrm{H}_{2} \mathrm{O}\right.$ were purchased from Sigma-Aldrich and used as received. $\mathrm{Ru}(\mathrm{bpy})_{2} \mathrm{Cl}_{2}$, $\mathrm{Ru}(\mathrm{dtb})_{2} \mathrm{Cl}_{2}, 4,4^{\prime}$-diethylester-2,2'-bipyridine (deeb), and [(pcymene $) \mathrm{Ru}(\mathrm{deeb}) \mathrm{Cl}] \mathrm{Cl}$ were prepared following a literature procedure. ${ }^{53-56}$

Synthesis. 4,4'-Ditrifluoromethyl-2,2'-bipyridine (btfmb). The method of Kubiak et al. ${ }^{57}$ was modified to synthesize this ligand first reported by Furue. ${ }^{58}$ A mixture of 2-bromo-4-(trifluoromethyl)pyridine (1g, $4.4 \mathrm{mmol}), \mathrm{Pd}(\mathrm{OAc})_{2}$ (50 mg, $\left.0.22 \mathrm{mmol}\right)$, TBAI (1.63 g, 4.4 $\mathrm{mmol}), \mathrm{K}_{2} \mathrm{CO}_{3}(916 \mathrm{mg}, 6.6 \mathrm{mmol})$, and $i-\mathrm{PrOH}(0.68 \mathrm{~mL}, 8.8 \mathrm{mmol})$ in $15 \mathrm{~mL}$ of DMF was heated at $100{ }^{\circ} \mathrm{C}$ for $20 \mathrm{~h}$. The heating was suspended, and the reaction mixture was filtered through a fine frit. Then $50 \mathrm{~mL}$ of DCM was added to the filtrate and was washed with deionized water $(50 \mathrm{~mL} \times 3)$. The organic layer was collected, and the water layer was further extracted with $20 \mathrm{~mL}$ of DCM. The combined organic layer was dried with anhydrous $\mathrm{MgSO}_{4}$, and concentrated to dryness on rotary evaporator. The crude was dissolved in $2 \mathrm{~mL}$ of DCM, and loaded onto a silica gel column $(4 \mathrm{~cm} \times 15 \mathrm{~cm})$ using hexane/ethyl acetate $(\mathrm{v}: \mathrm{v}$ $=10: 1)$ as eluent. The first colorless band was collected and concentrated to dryness to afford $520 \mathrm{mg}$ of white solid as product. $\left(\right.$ Yield $=81 \%$. ${ }^{1} \mathrm{H} \mathrm{NMR}\left(400 \mathrm{MHz}, \mathrm{CDCl}_{3}\right) \delta 8.88(\mathrm{~d}, J=5.0 \mathrm{~Hz}, 2 \mathrm{H})$, $8.73(\mathrm{~s}, 2 \mathrm{H}), 7.59(\mathrm{~d}, J=4.9 \mathrm{~Hz}, 2 \mathrm{H}) .{ }^{13} \mathrm{C} \mathrm{NMR}\left(101 \mathrm{MHz}, \mathrm{CDCl}_{3}\right) \delta$ $156.23,150.42$, 139.92, 139.58, 124.33, 121.62, 120.11, 120.07, 120.04, 120.00, 117.34, 117.31, 117.27, 117.23.

4-Ethylester-4'-carboxy-2,2'-bipyridine (mcb). The deeb ligand (1 $\mathrm{g}, 3.3 \mathrm{mmol}$ ) was dissolved in $100 \mathrm{~mL}$ of THF. To the mixture, $40 \mathrm{~mL}$ of $\mathrm{EtOH}$ and $5 \mathrm{~mL}$ of aqueous solution of $\mathrm{NaOH}(200 \mathrm{mg}, 5 \mathrm{mmol})$ were added sequentially. The mixture was purged with Ar for $30 \mathrm{~min}$ and allowed to stir at RT for $24 \mathrm{~h}$. The solvent was removed on a rotary evaporator, and the crude was redissolved in $30 \mathrm{~mL}$ of deionized water. An amount of $830 \mathrm{mg}$ of unreacted deeb was recovered by filtration through a medium frit. $\mathrm{HCl}(1 \mathrm{M})$ was added dropwise to the filtrate to adjust $\mathrm{pH}=3.8$, at which point a large amount of white solid precipitated out of the solution. The suspension was filtered through a medium frit and then rinsed with water $(\mathrm{pH}=3.8)$. The filter cake was dried in vacuum oven to afford $147 \mathrm{mg}$ of white solid product. (Yield $=94 \%$.) ${ }^{1} \mathrm{H}$ NMR (400 MHz, DMSO- $\left.d_{6}\right) \delta 13.84(\mathrm{~s}, \mathrm{br}, 1 \mathrm{H}), 8.93(\mathrm{t}, J=5.2 \mathrm{~Hz}$, $2 \mathrm{H}), 8.84(\mathrm{~s}, 2 \mathrm{H}), 7.93(\mathrm{td}, J=5.4,1.6 \mathrm{~Hz}, 2 \mathrm{H}), 4.42(\mathrm{q}, J=7.1 \mathrm{~Hz}, 2 \mathrm{H})$, $1.38(\mathrm{t}, J=7.1 \mathrm{~Hz}, 3 \mathrm{H}) .{ }^{13} \mathrm{C}$ NMR $\left(101 \mathrm{MHz}, \mathrm{DMSO}-d_{6}\right) \delta 165.99$, $164.49,155.60,155.34,150.82,150.69,138.50,123.59,123.27,119.59$, $119.18,61.81,14.07$.

$\mathrm{Ru}(\mathrm{btfmb})_{2} \mathrm{Cl}_{2}$. A mixture of $\mathrm{RuCl}_{3} \cdot 3 \mathrm{H}_{2} \mathrm{O}(225 \mathrm{mg}, 0.86 \mathrm{mmol})$, btfmb $(500 \mathrm{mg}, 1.71 \mathrm{mmol})$, and predried $\mathrm{LiCl}(220 \mathrm{mg}, 5.2 \mathrm{mmol})$ in $10 \mathrm{~mL}$ of DMF was purged with Ar for $20 \mathrm{~min}$, and was heated at reflux for $12 \mathrm{~h}$ under $\mathrm{Ar}$ atmosphere. DMF was removed on a rotary 
evaporator, and the crude product was extracted with DCM to remove $\mathrm{LiCl}$. DCM was removed on a rotary evaporator, and the obtained solid was redissolved in minimum amount of DCM and loaded onto a silica gel column $(4 \mathrm{~cm} \times 20 \mathrm{~cm})$ using DCM/hexane $(\mathrm{v}: \mathrm{v}=2: 1)$ as eluent. After removing a fast moving light yellow band, the eluent was changed to DCM/ethyl acetate ( $\mathrm{v}: \mathrm{v}=2: 1$ ), and the dark green band was collected, concentrated to dryness in vacuo to afford $450 \mathrm{mg}$ of black solid as product. (Yield $=69 \%$.) ${ }^{1} \mathrm{H}$ NMR $\left(400 \mathrm{MHz}\right.$, acetone- $\left.d_{6}\right) \delta$ $10.44(\mathrm{~d}, J=6.0 \mathrm{~Hz}, 2 \mathrm{H}), 9.21(\mathrm{~d}, J=2.0 \mathrm{~Hz}, 2 \mathrm{H}), 9.06(\mathrm{~d}, J=1.9 \mathrm{~Hz}$, $2 \mathrm{H}), 8.20(\mathrm{~d}, J=6.1 \mathrm{~Hz}, 2 \mathrm{H}), 8.14(\mathrm{dd}, J=6.0,1.9 \mathrm{~Hz}, 2 \mathrm{H}), 7.43(\mathrm{dd}, J=$ 6.1, $1.9 \mathrm{~Hz}, 2 \mathrm{H}) .{ }^{13} \mathrm{C}$ NMR (101 MHz, acetone- $\left.d_{6}\right) \delta 206.18,161.84$, $160.06,156.09,155.06,136.77,136.43,135.55,135.21,125.47,125.17$, $122.76,122.24,122.21,121.96,120.67,120.63,120.60,120.56,120.32$, 120.28 .

$\left[R u(b p y)_{2}(\right.$ deeb $\left.)\right]\left(\mathrm{PF}_{6}\right)_{2}$. A mixture of $\mathrm{Ru}(\mathrm{bpy})_{2} \mathrm{Cl}_{2}(242 \mathrm{mg}, 0.50$ $\mathrm{mmol})$, deeb $(160 \mathrm{mg}, 0.53 \mathrm{mmol})$, and $15 \mathrm{~mL}$ of EtOH in a $25 \mathrm{~mL}$ microwave vessel was purged with Ar for $20 \mathrm{~min}$, and was heated at 130 ${ }^{\circ} \mathrm{C}$ for $30 \mathrm{~min}$ in Anton Parr microwave reactor. The solvent was removed on a rotary evaporator, and the reaction mixture was redissolved in $10 \mathrm{~mL}$ of deionized water. The solution was filtered through a fine frit to remove excess of deeb. An amount of $326 \mathrm{mg}$ $\mathrm{NH}_{4} \mathrm{PF}_{6}(2 \mathrm{mmol})$ in $2 \mathrm{~mL}$ of deionized water was added to the filtrate to form a dark orange solid precipitate. The suspension was allowed to stir vigorously at RT for 15 min followed by filtering through a fine frit. The filter cake was rinsed with $30 \mathrm{~mL}$ of deionized water and dried in vacuum oven to afford $370 \mathrm{mg}$ of dark orange solid. (Yield $=74 \%$.) ${ }^{1} \mathrm{H}$ $\operatorname{NMR}\left(400 \mathrm{MHz}, \mathrm{CD}_{3} \mathrm{CN}-d_{3}\right) \delta 9.03(\mathrm{dd}, J=1.9,0.7 \mathrm{~Hz}, 2 \mathrm{H}), 8.50(\mathrm{ddt}$, $J=8.1,4.2,1.1 \mathrm{~Hz}, 4 \mathrm{H}), 8.08(\mathrm{qd}, J=7.6,1.5 \mathrm{~Hz}, 4 \mathrm{H}), 7.94(\mathrm{dd}, J=5.8$, $0.7 \mathrm{~Hz}, 2 \mathrm{H}), 7.82(\mathrm{dd}, J=5.9,1.7 \mathrm{~Hz}, 2 \mathrm{H}), 7.70(\mathrm{ddd}, J=5.6,1.5,0.7 \mathrm{~Hz}$, $2 \mathrm{H}), 7.66$ (ddd, $J=5.6,1.5,0.7 \mathrm{~Hz}, 2 \mathrm{H}), 7.42(\mathrm{ddd}, J=7.6,5.6,1.3 \mathrm{~Hz}$, $2 \mathrm{H}), 7.38(\mathrm{ddd}, J=7.7,5.6,1.3 \mathrm{~Hz}, 2 \mathrm{H}), 4.46(\mathrm{q}, J=7.1 \mathrm{~Hz}, 4 \mathrm{H}), 1.41(\mathrm{t}$, $J=7.1 \mathrm{~Hz}, 6 \mathrm{H}) \cdot{ }^{13} \mathrm{C}$ NMR $\left(101 \mathrm{MHz}, \mathrm{CD}_{3} \mathrm{CN}-d_{3}\right) \delta 164.40,158.68$, $157.71,157.59,153.81,152.78,152.54,139.79,139.24,128.74,128.65$, 127.42, 125.38, 124.59, 63.62, 14.39. HR-ESI-MS: $m / z=343.0615$ (calcd. for $\left[\mathrm{RuC}_{34} \mathrm{H}_{28} \mathrm{~N}_{6} \mathrm{O}_{4}\right]^{2+}\left(\left[\mathrm{Ru}(\mathrm{bpy})_{2}(\mathrm{dcb})-\mathrm{C}_{2} \mathrm{H}_{4}\right]^{2+}\right)$ : 342.8521).

$\left[R u(d t b)_{2}(\right.$ deeb $\left.)\right]\left(P F_{6}\right)_{2}$. A mixture of $[(\mathrm{p}$-cymene $) \mathrm{Ru}($ deeb $) \mathrm{Cl}] \mathrm{Cl}$ (606 mg, $1 \mathrm{mmol}$ ), 4,4-di-tert-butyl-2,2'-bipyridine (dtb, $540 \mathrm{mg}, 2$ $\mathrm{mmol}$ ), and $\mathrm{AgNO}_{3}(375 \mathrm{mg}, 2.2 \mathrm{mmol})$ in $30 \mathrm{~mL}$ of EtOH was purged with Ar for $20 \mathrm{~min}$, and was heated at reflux for $8 \mathrm{~h}$. The reaction mixture was condensed to $10 \mathrm{~mL}$ and filtered through a fine frit to remove $\mathrm{AgCl}$. $\mathrm{NH}_{4} \mathrm{PF}_{6}(500 \mathrm{mg}, 3 \mathrm{mmol})$ in $2 \mathrm{~mL}$ of deionized water was added to the filtrate to form a dark orange precipitate. The suspension was allowed to stir at RT for $15 \mathrm{~min}$, followed by filtering through a fine frit. The obtained filter cake was dried in vacuo and recrystallized from DCM/ ether to afford $1 \mathrm{~g}$ of dark orange solid as product. (Yield $=81 \%$.) ${ }^{1} \mathrm{H}$ NMR $\left(400 \mathrm{MHz}, \mathrm{CD}_{3} \mathrm{CN}-d_{6}\right) \delta 9.02(\mathrm{~d}, J=1.0 \mathrm{~Hz}, 2 \mathrm{H}), 8.48(\mathrm{dd}, J=$ $7.1,2.0 \mathrm{~Hz}, 4 \mathrm{H}), 7.90(\mathrm{~d}, J=5.9 \mathrm{~Hz}, 2 \mathrm{H}), 7.83(\mathrm{dd}, J=5.8,1.7 \mathrm{~Hz}, 2 \mathrm{H})$, $7.52(\mathrm{dd}, J=9.9,6.0 \mathrm{~Hz}, 4 \mathrm{H}), 7.42(\mathrm{dd}, J=6.0,2.0 \mathrm{~Hz}, 2 \mathrm{H}), 7.34(\mathrm{dd}, J=$ $6.0,2.0 \mathrm{~Hz}, 2 \mathrm{H}), 4.46(\mathrm{q}, J=7.1 \mathrm{~Hz}, 4 \mathrm{H}), 1.44-1.36(\mathrm{~m}, 42 \mathrm{H}) .{ }^{13} \mathrm{C}$ NMR $\left(400 \mathrm{MHz}, \mathrm{CD}_{3} \mathrm{CN}-d_{6}\right) \delta 164.5,164.0,158.8,157.5,153.5,152.0$, 151.6, 139.4, 127.3, 125.69, 125.6, 124.4, 122.6, 73.1, 63.6, 36.3, 30.4, 14.4. HR-ESI-MS: $m / z=1083.3638$ (calcd. for $\left[\mathrm{C}_{52} \mathrm{H}_{64} \mathrm{~N}_{6} \mathrm{O}_{4} \mathrm{PF}_{6}\right]^{+}$ $\left.\left(\left[\mathrm{Ru}(\mathrm{dtb})_{2}(\mathrm{deeb})\right]\left(\mathrm{PF}_{6}\right)^{+}\right): 1083.1521\right) ; m / z=469.2004$ (calcd. for $\left.\left[\mathrm{C}_{52} \mathrm{H}_{64} \mathrm{~N}_{6} \mathrm{O}_{4}\right]^{2+}\left(\left[\mathrm{Ru}(\mathrm{dtb})_{2}(\text { deeb })\right]^{2+}\right): 469.0940\right)$.

$\left[R u(b t f m b)_{2}(\right.$ deeb $\left.)\right]\left(P F_{6}\right)_{2}$. A mixture of $\mathrm{Ru}(\mathrm{btfmb})_{2} \mathrm{Cl}_{2}(120 \mathrm{mg}$, $0.16 \mathrm{mmol})$, deeb $(48 \mathrm{mg}, 0.16 \mathrm{mmol}), \mathrm{AgNO}_{3}(60 \mathrm{mg}, 0.35 \mathrm{mmol})$, and $14 \mathrm{~mL}$ of EtOH in a $25 \mathrm{~mL}$ microwave vessel was purged with Ar for $20 \mathrm{~min}$, and was heated at $160^{\circ} \mathrm{C}$ for $1 \mathrm{~h}$ in an Anton Parr microwave reactor. $\mathrm{AgCl}$ was removed by filtering through a fine frit, and $100 \mathrm{mg}$ (0.61 mmol) of $\mathrm{NH}_{4} \mathrm{PF}_{6}$ in $2 \mathrm{~mL}$ of deionized water was added to the filtrate to form an orange precipitate. The suspension was allowed to stir at RT for $15 \mathrm{~min}$, followed by filtering through a fine frit. The filter cake was rinsed with water and ethanol sequentially, and dried in vacuum oven to afford $174 \mathrm{mg}$ of orange solid as product. (Yield $=86 \%$.) ${ }^{1} \mathrm{H}$ NMR $\left(400 \mathrm{MHz}, \mathrm{CD}_{3} \mathrm{CN}-d_{3}\right) \delta 9.07(\mathrm{~d}, J=1.7 \mathrm{~Hz}, 2 \mathrm{H}), 8.95(\mathrm{~s}, 4 \mathrm{H})$, $7.98(\mathrm{~d}, J=5.9 \mathrm{~Hz}, 2 \mathrm{H}), 7.93(\mathrm{~d}, J=5.9 \mathrm{~Hz}, 2 \mathrm{H}), 7.89(\mathrm{~d}, J=5.8 \mathrm{~Hz}$, $2 \mathrm{H}), 7.85(\mathrm{dd}, J=5.8,1.7 \mathrm{~Hz}, 2 \mathrm{H}), 7.70(\mathrm{ddd}, J=12.6,5.9,1.9 \mathrm{~Hz}, 4 \mathrm{H})$, $4.47(\mathrm{q}, J=7.1 \mathrm{~Hz}, 4 \mathrm{H}), 1.41(\mathrm{t}, J=7.1 \mathrm{~Hz}, 6 \mathrm{H}) .{ }^{13} \mathrm{C} \mathrm{NMR}(101 \mathrm{MHz}$, $\left.\mathrm{CD}_{3} \mathrm{CN}-d_{3}\right) \delta 164.26,158.36,158.28,158.17,154.99,154.76,154.36$,
$140.97,140.29,139.96,127.79,125.12,124.98,122.67,63.78,14.38$. HR-ESI-MS: $m / z=479.0371$ (calcd. for $\left[\mathrm{RuC}_{38} \mathrm{H}_{24} \mathrm{~N}_{6} \mathrm{O}_{4} \mathrm{~F}_{12}\right]^{2+}$ $\left(\left[\mathrm{Ru}(\mathrm{btfmb})_{2}(\mathrm{dcb})-\mathrm{C}_{2} \mathrm{H}_{4}\right]^{2+}\right):$ 478.8486).

$\left[R u(b p y)_{2}(d c b)\right]\left(P F_{6}\right)_{2}$. $\quad\left[\mathrm{Ru}(\mathrm{bpy})_{2}(\mathrm{deeb})\right]\left(\mathrm{PF}_{6}\right)_{2} \quad(170 \mathrm{mg}, 0.17$ $\mathrm{mmol}$ ) was dissolved in $15 \mathrm{~mL}$ of acetone, and $5 \mathrm{~mL}$ of $0.5 \mathrm{M}$ aqueous $\mathrm{NaOH}$ solution was added. The mixture was purged with $\mathrm{Ar}$ for $15 \mathrm{~min}$ and was heated at $55{ }^{\circ} \mathrm{C}$ overnight. Acetone was removed on a rotary evaporator, and $1 \mathrm{M} \mathrm{HPF}_{6}$ aqueous solution was added to the solution to adjust the $\mathrm{pH}=1$, causing dark orange precipitate, which was collected by filtration through a fine frit, rinsed with deionized water, and dried in vacuum oven to afford $135 \mathrm{mg}$ of product. (Yield $=84 \%$.) ${ }^{1} \mathrm{H}$ NMR (400 $\left.\mathrm{MHz}, \mathrm{CD}_{3} \mathrm{CN}-d_{3}\right) \delta 9.09(\mathrm{~s}, 2 \mathrm{H}), 8.50(\mathrm{dd}, J=8.2,3.8 \mathrm{~Hz}, 4 \mathrm{H}), 8.12-$ $8.03(\mathrm{~m}, 4 \mathrm{H}), 7.92(\mathrm{~d}, J=5.8 \mathrm{~Hz}, 2 \mathrm{H}), 7.82(\mathrm{dd}, J=5.8,1.7 \mathrm{~Hz}, 2 \mathrm{H})$, $7.70(\mathrm{dd}, J=5.7,1.3 \mathrm{~Hz}, 2 \mathrm{H}), 7.67-7.64(\mathrm{~m}, 2 \mathrm{H}), 7.42(\mathrm{ddd}, J=7.2,5.7$, $1.3 \mathrm{~Hz}, 2 \mathrm{H}), 7.38(\mathrm{ddd}, J=7.2,5.6,1.3 \mathrm{~Hz}, 2 \mathrm{H}) .{ }^{13} \mathrm{C}$ NMR $(101 \mathrm{MHz}$, $\left.\mathrm{CD}_{3} \mathrm{CN}-d_{3}\right) \delta 165.00,158.65,157.72,157.60,153.72,152.76,152.53$, $139.90,139.22,128.73,128.66,127.71,125.37,124.90$.

$\left[R u(d t b)_{2}(d c b)\right]\left(P_{6}\right)_{2}$. A mixture of $\left[\mathrm{Ru}(\mathrm{deeb})(\mathrm{dtb})_{2}\right]\left(\mathrm{PF}_{6}\right)_{2}(400$ $\mathrm{mg}, 0.33 \mathrm{mmol}$ ), and $5 \mathrm{~mL}$ of $0.5 \mathrm{M}$ aqueous $\mathrm{NaOH}$ solution in $30 \mathrm{~mL}$ of acetone was purged with $\mathrm{N}_{2}$ for $15 \mathrm{~min}$ and was heated at $55^{\circ} \mathrm{C}$ for $12 \mathrm{~h}$. The reaction mixture was filtered through a fine frit and rinsed with 10 $\mathrm{mL}$ of deionized water. Acetone was removed from the filtrate on rotary evaporator, and $30 \mathrm{~mL}$ of deionized water was added to dissolve the crude product. To this solution $\mathrm{HPF}_{6}(1 \mathrm{M})$ was added dropwise to adjust the $\mathrm{pH}=1$ to form an orange brown precipitate. The precipitate was collected on a fine frit by filtration, rinsed with deionized water and dried in vacuum oven affording $330 \mathrm{mg}$ of product. (Yield $=85 \%$.) ${ }^{1} \mathrm{H}$ NMR $\left(400 \mathrm{MHz}, \mathrm{CD}_{3} \mathrm{CN}-d_{3}\right) \delta 9.02(\mathrm{~s}, 2 \mathrm{H}), 8.48(\mathrm{dd}, J=6.6,2.0 \mathrm{~Hz}$, $4 \mathrm{H}), 7.90(\mathrm{~d}, J=5.9 \mathrm{~Hz}, 2 \mathrm{H}), 7.83(\mathrm{dd}, J=5.8,1.6 \mathrm{~Hz}, 2 \mathrm{H}), 7.53(\mathrm{dd}, J=$ $10.9,6.1 \mathrm{~Hz}, 4 \mathrm{H}), 7.43(\mathrm{dd}, J=6.1,1.9 \mathrm{~Hz}, 2 \mathrm{H}), 7.35(\mathrm{dd}, J=6.1,2.0 \mathrm{~Hz}$, $2 \mathrm{H}), 1.42(2,18 \mathrm{H}), 1.39(2,18 \mathrm{H}) .{ }^{13} \mathrm{C} \mathrm{NMR}\left(101 \mathrm{MHz}, \mathrm{CD}_{3} \mathrm{CN}-d_{3}\right) \delta$ $166.1,163.8,158.9,157.5,157.5,153.1,152.8,152.0,151.6,127.6,125.7$, 125.6, 124.9, 122.5, 36.3, 30.41. HR-ESI-MS: $\mathrm{m} / z=1027.3028$ (calcd. for $\left.\left[\mathrm{RuC}_{48} \mathrm{H}_{56} \mathrm{~N}_{6} \mathrm{O}_{4} \mathrm{PF}_{6}\right]^{+}\left(\left[\mathrm{Ru}(\mathrm{dtb})_{2}(\mathrm{dcb})\left(\mathrm{PF}_{6}\right)\right]^{+}\right): 1027.0446\right) ; \mathrm{m} / z$ $=441.1691$ (calcd. for $\left[\mathrm{RuC}_{48} \mathrm{H}_{56} \mathrm{~N}_{6} \mathrm{O}_{4}\right]^{2+}\left(\left[\mathrm{Ru}(\mathrm{dtb})_{2}(\mathrm{dcb})\right]^{2+}\right)$ : 441.0402).

$\left[R u(b t f m b)_{2}(d c b)\right]\left(P F_{6}\right)_{2}$. A mixture of $\mathrm{Ru}(\mathrm{btfmb})_{2}(\mathrm{deeb})\left(\mathrm{PF}_{6}\right)_{2}$ (110 mg, $0.086 \mathrm{mmol}), \mathrm{Et}_{3} \mathrm{~N}(0.5 \mathrm{~mL}), \mathrm{H}_{2} \mathrm{O}(1 \mathrm{~mL})$, and acetone $(5$ $\mathrm{mL}$ ) was purged with $\mathrm{Ar}$ for $20 \mathrm{~min}$, and was then heated at $55{ }^{\circ} \mathrm{C}$ overnight. After that the solvent was removed on a rotary evaporator, and the crude was redissolved in $5 \mathrm{~mL}$ of deionized water. To the mixture, $1 \mathrm{M} \mathrm{HPF}_{6}$ aqueous solution was added to tune the $\mathrm{pH}=1$ causing an orange precipitate, which was collected on a fine frit, followed by rinsing with water and drying in vacuo to afford $96 \mathrm{mg}$ of product. (Yield $=92 \%$.) ${ }^{1} \mathrm{H}$ NMR $\left(400 \mathrm{MHz}, \mathrm{D}_{2} \mathrm{O}\right) \delta 9.02(\mathrm{~d}, J=3.8 \mathrm{~Hz}, 4 \mathrm{H})$, $8.93(\mathrm{~s}, 2 \mathrm{H}), 8.10(\mathrm{dd}, J=12.1,5.9 \mathrm{~Hz}, 4 \mathrm{H}), 7.86-7.77(\mathrm{~m}, 6 \mathrm{H}), 7.74$ $(\mathrm{dd}, J=5.9,1.6 \mathrm{~Hz}, 2 \mathrm{H}) \cdot{ }^{13} \mathrm{C}$ NMR $\left(101 \mathrm{MHz}, \mathrm{D}_{2} \mathrm{O}\right) \delta 171.23,158.11$, $157.98,157.62,153.74,153.67,152.42,147.14,139.87,139.52,127.12$, $124.61,124.17,123.93,122.06,121.21$. HR-ESI-MS: $m / z=465.0214$ (calcd. for $\left[\mathrm{RuC}_{36} \mathrm{H}_{20} \mathrm{~N}_{6} \mathrm{O}_{4} \mathrm{~F}_{12}\right]^{2+}\left(\left[\mathrm{Ru}(\mathrm{btfmb})_{2}(\mathrm{dcb})\right]^{2+}\right): 464.8217$.

$\left[R u(b p y)_{2}(m c b)\right]\left(P F_{6}\right)_{2}$. Ru(bpy $)_{2} \mathrm{Cl}_{2}(70 \mathrm{mg}, 0.15 \mathrm{mmol}), \mathrm{mcb}(40$ $\mathrm{mg}, 0.15 \mathrm{mmol}$ ) and $6 \mathrm{~mL}$ EtOH was added into a $10 \mathrm{~mL}$ microwave vessel. The mixture was purged with $\mathrm{Ar}$ for $20 \mathrm{~min}$ and was heated at 140 ${ }^{\circ} \mathrm{C}$ for $45 \mathrm{~min}$ in an Anton Parr microwave reactor. The solvent was removed on rotary evaporator, and the crude product was redissolved in $\sim 5 \mathrm{~mL}$ of deionized water. The solution was filtered through a fine frit to remove unreacted starting materials. An mount of $95 \mathrm{mg}$ of $\mathrm{NH}_{4} \mathrm{PF}_{6}$ $(0.6 \mathrm{mmol})$ in $1 \mathrm{~mL}$ of water was added to the filtrate to create an orange suspension. The mixture was stirred at RT for 15 min followed by filtering through a medium frit. The filter cake was rinsed with deionized water and dried in vacuum oven affording $100 \mathrm{mg}$ of orange solid as product. (Yield $=71 \%$. ${ }^{1} \mathrm{H}$ NMR $\left(400 \mathrm{MHz}, \mathrm{CD}_{3} \mathrm{CN}-d_{3}\right) \delta 9.05(\mathrm{~d}, J=$ $1.6 \mathrm{~Hz}, 1 \mathrm{H}), 9.00(\mathrm{~d}, J=1.7 \mathrm{~Hz}, 1 \mathrm{H}), 8.50(\mathrm{dt}, J=7.0,2.9 \mathrm{~Hz}, 4 \mathrm{H})$, $8.14-7.99(\mathrm{~m}, 4 \mathrm{H}), 7.93(\mathrm{~d}, J=5.9 \mathrm{~Hz}, 1 \mathrm{H}), 7.89(\mathrm{~d}, J=5.8 \mathrm{~Hz}, 1 \mathrm{H})$, $7.84(\mathrm{dd}, J=5.8,1.6 \mathrm{~Hz}, 1 \mathrm{H}), 7.80(\mathrm{dd}, J=5.8,1.7 \mathrm{~Hz}, 1 \mathrm{H}), 7.70(\mathrm{~d}, J=$ $5.6 \mathrm{~Hz}, 2 \mathrm{H}), 7.67(\mathrm{t}, J=5.9 \mathrm{~Hz}, 2 \mathrm{H}), 7.45-7.34(\mathrm{~m}, 4 \mathrm{H}), 4.44(\mathrm{q}, J=7.1$ $\mathrm{Hz}, 2 \mathrm{H}), 1.40(\mathrm{t}, J=7.1 \mathrm{~Hz}, 3 \mathrm{H}) .{ }^{13} \mathrm{C} \mathrm{NMR}\left(101 \mathrm{MHz}, \mathrm{CD}_{3} \mathrm{CN}-d_{3}\right) \delta$ $164.44,157.74,157.66,153.74,153.46,152.76,152.55$, 139.72, 139.16, $128.70,128.65,127.90,127.26,125.34,124.94,124.42,63.59,30.84$, 14.38. HR-ESI-MS: $m / z=685.1113$ (calcd. for $\left[\mathrm{RuC}_{34} \mathrm{H}_{27} \mathrm{~N}_{6} \mathrm{O}_{4}\right]^{+}$ 

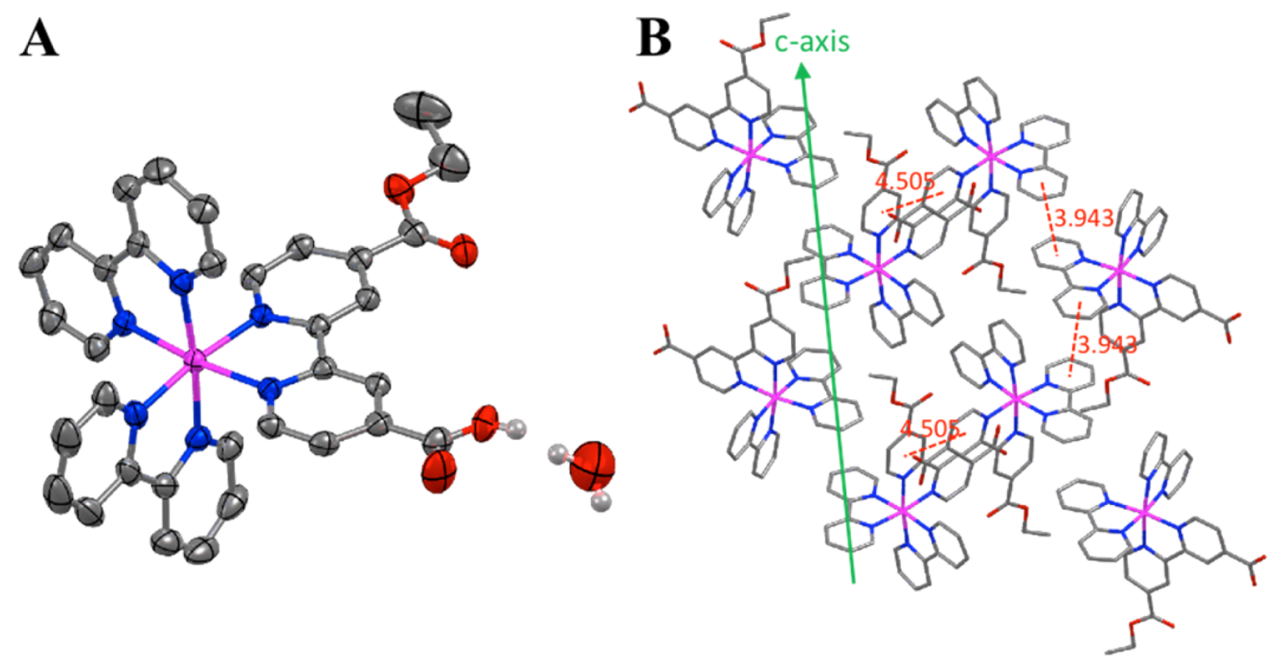

Figure 2. (A) Crystal structure of $\left[\mathrm{Ru}(\mathrm{bpy})_{2}(\mathrm{mcb})\right]\left(\mathrm{PF}_{6}\right)_{2}$. Thermal ellipsoids at the $50 \%$ probability level. Anions and all hydrogen atoms are omitted for clarity purpose except for the ones on the carboxylic acid group and water molecule. Color code: Pink, Ru; blue, N; red, O; gray, C; light gray, H. (B) Crystal packing along $c$-axis; the red dashed lines represent the centroid distances between two stacked pyridine rings.

$\left.\left(\left[\mathrm{Ru}(\mathrm{bpy})_{2}(\mathrm{mcb})-\mathrm{H}\right]^{+}\right): 684.6962\right) ; m / z=343.0599$ (calcd. for $\left.\left[\mathrm{RuC}_{34} \mathrm{H}_{28} \mathrm{~N}_{6} \mathrm{O}_{4}\right]^{2+}\left(\left[\mathrm{Ru}(\mathrm{bpy})_{2}(\mathrm{mcb})\right]^{2+}\right): 342.8521\right)$.

$\left[R u(d t b)_{2}(m c b)\right]\left(P F_{6}\right)_{2}$. A mixture of $\mathrm{Ru}(\mathrm{dtb})_{2} \mathrm{Cl}_{2}(104 \mathrm{mg}, 0.15$ $\mathrm{mmol})$, mcb (40 mg, $0.15 \mathrm{mmol})$, and $6 \mathrm{~mL}$ of $\mathrm{EtOH}$ in a $10 \mathrm{~mL}$ microwave vessel was purged with Ar for $20 \mathrm{~min}$ and was heated at 140 ${ }^{\circ} \mathrm{C}$ for $45 \mathrm{~min}$ in an Anton Parr microwave reactor. The solvent was condensed to $\sim 5 \mathrm{~mL}$, and $95 \mathrm{mg}$ of $\mathrm{NH}_{4} \mathrm{PF}_{6}(0.58 \mathrm{mmol})$ in $2 \mathrm{~mL}$ of deionized water was added to form an orange brown precipitate. The mixture was allowed to stir at RT for $15 \mathrm{~min}$, followed by filtering through a medium frit. The filter cake was dried in a vacuum oven, and was then recrystallized in acetone/diethyl ether twice to afford $80 \mathrm{mg}$ of product as an orange-brown solid. (Yield $=50 \%$.) ${ }^{1} \mathrm{H}$ NMR $(400 \mathrm{MHz}$, $\left.\mathrm{CD}_{3} \mathrm{CN}-d_{3}\right) \delta 9.04(\mathrm{~s}, 1 \mathrm{H}), 9.00(\mathrm{~s}, 1 \mathrm{H}), 8.47(\mathrm{dd}, J=6.2,3.0 \mathrm{~Hz}, 4 \mathrm{H})$, $7.93-7.78(\mathrm{~m}, 4 \mathrm{H}), 7.59-7.48(\mathrm{~m}, 4 \mathrm{H}), 7.42(\mathrm{dd}, J=6.2,2.0 \mathrm{~Hz}, 2 \mathrm{H})$, $7.34(\mathrm{~d}, J=6.0 \mathrm{~Hz}, 2 \mathrm{H}), 4.45(\mathrm{q}, J=7.1 \mathrm{~Hz}, 2 \mathrm{H}), 1.44-1.37(\mathrm{~m}, 39 \mathrm{H})$. ${ }^{13} \mathrm{C}$ NMR $\left(101 \mathrm{MHz}, \mathrm{CD}_{3} \mathrm{CN}-d_{3}\right) \delta 164.51,163.96,159.04,158.47$, $157.53,157.44,153.42,153.17,152.01,151.60,139.30,127.78,127.17$, $125.71,125.63,124.81,124.29,122.58,63.56,36.32,30.42$, 14.39. HRESI-MS: $m / z=909.3626$ (calcd. for $\left[\mathrm{RuC}_{50} \mathrm{H}_{59} \mathrm{~N}_{6} \mathrm{O}_{4}\right]^{+}([\mathrm{Ru}-$ $\left.\left.\left.(\mathrm{dtb})_{2}(\mathrm{mcb})-\mathrm{H}\right]^{+}\right): 909.1263\right) ; m / z=455.1848$ (calcd. for $\left.\left[\mathrm{RuC}_{50} \mathrm{H}_{60} \mathrm{~N}_{6} \mathrm{O}_{4}\right]^{2+}\left(\left[\mathrm{Ru}(\mathrm{dtb})_{2}(\mathrm{mcb})\right]^{2+}\right): 455.0671\right)$.

$\left[R u(b t f m b)_{2}(m c b)\right]\left(\mathrm{NO}_{3}\right)_{2}$. A mixture of $\mathrm{Ru}(\mathrm{btfmb})_{2} \mathrm{Cl}_{2}(168 \mathrm{mg}$, $0.22 \mathrm{mmol}), \mathrm{mcb}(60 \mathrm{mg}, 0.22 \mathrm{mmol}), \mathrm{AgNO}_{3}(45 \mathrm{mg}, 0.27 \mathrm{mmol})$, and $10 \mathrm{~mL}$ if EtOH in a $25 \mathrm{~mL}$ microwave vessel was purged with Ar for 20 min, and was then heated at $140^{\circ} \mathrm{C}$ for $2 \mathrm{~h}$ in an Anton Parr microwave reactor. $\mathrm{AgCl}$ was removed by by filtering through a fine frit, and the filtrate was concentrated to drynss on rotary evaporator. A volume of $100 \mathrm{~mL}$ of DCM was added to the crude to extract the impurity. The DCM solution was separated from the undissolved orange solid, condensed to $\sim 20 \mathrm{~mL}$, and placed in a freezer overnight. The orange solid that precipitated out from DCM solution was combined with the original undissolved solid. The combined solid was dissolved in $5 \mathrm{~mL}$ of acetone, and excess $\mathrm{AgNO}_{3}$ was removed by filtration. The filtrate was recrystallized in acetone/ether twice to afford $120 \mathrm{mg}$ of red-orange solid as product. (Yield $=50 \%$.) ${ }^{1} \mathrm{H}$ NMR $\left(400 \mathrm{MHz}\right.$, methanol- $\left.d_{4}\right) \delta$ $9.36(\mathrm{~s}, 4 \mathrm{H}), 9.17-9.08(\mathrm{~m}, 2 \mathrm{H}), 8.15(\mathrm{t}, J=5.8 \mathrm{~Hz}, 2 \mathrm{H}), 8.12(\mathrm{~d}, J=6.0$ $\mathrm{Hz}, 1 \mathrm{H}), 8.08(\mathrm{~d}, J=6.0 \mathrm{~Hz}, 1 \mathrm{H}), 8.02(\mathrm{~d}, J=5.8 \mathrm{~Hz}, 1 \mathrm{H}), 7.96(\mathrm{dd}, J=$ $5.8,1.7 \mathrm{~Hz}, 1 \mathrm{H}), 7.91-7.80(\mathrm{~m}, 6 \mathrm{H}), 4.51(\mathrm{q}, J=7.1 \mathrm{~Hz}, 2 \mathrm{H}), 1.44(\mathrm{t}, J=$ $7.1 \mathrm{~Hz}, 3 \mathrm{H}) .{ }^{13} \mathrm{C}$ NMR $\left(101 \mathrm{MHz}, \mathrm{CD}_{3} \mathrm{OD}-d_{4}\right) \delta 164.48,159.36$, $159.26,159.22$, 159.17, 157.60, 154.88, 154.75, 154.61, 154.05, 153.24, $141.24,141.13,140.78,128.88,127.85,125.63,125.37,124.77,123.13$, 122.22, 63.93, 14.46. HR-ESI-MS: $m / z=479.0373$ (calcd. for $\left.\left[\mathrm{RuC}_{38} \mathrm{H}_{24} \mathrm{~N}_{6} \mathrm{O}_{4} \mathrm{~F}_{12}\right]^{2+}\left(\left[\mathrm{Ru}(\mathrm{btfmb})_{2}(\mathrm{mcb})\right]^{2+}\right): 478.8486\right)$.

Spectroscopy. UV-Visible Absorption. UV-visible absorption spectra were obtained on a Varian Cary 50 or an Agilent Cary 60 spectrophotometer at room temperature in $1.0 \mathrm{~cm}$ path length quartz cuvettes. Unless otherwise specified, the solutions were bubbled with argon gas for $>30 \mathrm{~min}$ prior to photoluminescence and transient absorption studies. The $\mathrm{pH}$ dependent absorption and PL spectra were obtained from $\mathrm{pH} 1$ to 14 . The $\mathrm{pH}$ was monitored in situ with an Oakton pH 11 m (Cole Parmer).

Steady-State Photoluminescence. Steady spectra were obtained with a HORIBA Fluorolog spectrophotometer equipped with a $450 \mathrm{~W}$ Xe arc lamp for the excitation source. PL spectra were obtained at room temperature with PL detected at a right angle to the excitation beam. Quantum yields were measured versus $\left[\mathrm{Ru}(\mathrm{bpy})_{3}\right] \mathrm{Cl}_{2}$ in water as the standard $\left(\phi_{\mathrm{PL}}=0.042\right)$ with the optically dilute method. ${ }^{59}$

Time-Resolved Experiments. Nanosecond transient absorption measurements were obtained with an apparatus similar to that which has been previously described. Briefly, samples were excited by a Qswitched, pulsed Nd:YAG laser (Quantel U.S.A. (BigSky) Brilliant B; $5-6 \mathrm{~ns}$ full width at half-maximum (fwhm), $1 \mathrm{~Hz}, \sim 10 \mathrm{~mm}$ in diameter) tuned to $532 \mathrm{~nm}$ with the appropriate nonlinear optics. The excitation fluence was measured with a thermopile power meter (Molectron) that was typically $3-5 \mathrm{~mJ} /$ pulse. A $150 \mathrm{~W}$ Xe arc lamp served as the probe beam and was aligned orthogonal to the laser excitation light. The probe lamp was pulsed for measurements on sub-100 $\mu$ s time scales. Detection was achieved with a monochromator (SPEX 1702/04) optically coupled to an R928 photomultiplier tube (Hamamatsu). Transient data was acquired with a computer-interfaced digital oscilloscope (LeCroy 9450, Dual $330 \mathrm{MHz}$ ) with an overall instrument response time of $\sim 10 \mathrm{~ns}$. Typically, 30 laser pulses were averaged at each observation wavelength over the range $340-750$ at $10 \mathrm{~nm}$ intervals. Full spectra were generated by averaging $2-10$ points on either side of the desired time value to reduce noise in the raw data. Time-resolved photoluminescence was obtained using the same experimental setup described above with the exception of the Xe arc lamp as the probe beam. PL signals were acquired at a right angle to excitation with pulsed $532 \mathrm{~nm}$ laser light, and fluence was typically $1 \mathrm{~mJ} /$ pulse. Typically, 300 laser shots were averaged and digitized on a computer-interfaced oscilloscope.

\section{RESULTS}

The six ruthenium polypyridyl compounds shown in Figure 1 were synthesized in high yield. The dcb containing compounds with dtb or bpy have been previously reported. ${ }^{27,60}$ The compounds with one ethyl ester group and one carboxylic acid group were newly synthesized. Crystals of $\left[\mathrm{Ru}(\mathrm{bpy})_{2}(\mathrm{mcb})\right]^{2+}$ suitable for single crystal diffraction studies were obtained and the refined structure is shown in Figure 2.

Each mcb ligand clearly possessed one ethyl ester group and one carboxylic acid group in the para position of each pyridine 
ring. The carboxylic acid group formed a hydrogen bond with a nearby water molecule as is shown. The average $\mathrm{Ru}-\mathrm{N}$ distance was $2.57 \AA$ with a $79.2^{\circ}$ average bite angle for the three ligands. Crystal packing propagates along the $c$-axis through $\pi-\pi$ interactions with a centroid distance of $3.94 \AA$ between the pyridine rings. ${ }^{61}$ Each $\mathrm{Ru}$ compound also showed evidence for weaker $\pi-\pi$ interactions between the mcb ligands, with an interlayer distance of $4.51 \AA$. The detailed crystal structure information is given in Table 1 .

Table 1. Crystallographic Data and Structure Refinement for $\left[\mathrm{Ru}(\mathrm{bpy})_{2}(\mathbf{m c b})\right]\left(\mathrm{PF}_{6}\right)_{2}$

$\begin{array}{ll}\text { empirical formula } & \mathrm{C}_{34} \mathrm{H}_{30} \mathrm{~F}_{12} \mathrm{~N}_{6} \mathrm{O}_{5} \mathrm{P}_{2} \mathrm{Ru} \\ \text { formula weight } & 993.65 \\ \text { temperature/K } & 100 \\ \text { crystal system } & \text { monoclinic } \\ \text { space group } & \mathrm{P} 21 / \mathrm{c} \\ a / \AA & 11.8405(3) \\ b / \AA & 24.0489(6) \\ c / \AA & 13.5875(4) \\ \alpha / \text { deg } & 90 \\ \beta / \text { deg } & 98.2170(17) \\ \gamma / \mathrm{deg} & 90 \\ \text { volume } / \AA^{3} & 3829.33(18) \\ Z & 4 \\ \rho_{\text {calc,g }} / \mathrm{cm}^{3} & 1.724 \\ \mu / \mathrm{mm}^{-1} & 5.105 \\ \text { crystal size } / \mathrm{mm}^{3} & 0.219 \times 0.129 \times 0.071 \\ \text { radiation } & \mathrm{Cu} \mathrm{K \alpha}(\lambda=1.54178) \\ \text { Final } R \text { indexes }[I \geq 2 \sigma(\mathrm{I})] & R 1=0.0516, w R 2=0.1266 \\ \text { final } R \text { indexes }[\text { all data }] & R 1=0.0576, w R 2=0.1302\end{array}$

All the ruthenium polypyridyl compounds displayed broad metal-to-ligand charge transfer (MLCT) absorption bands centered at $\sim 460 \mathrm{~nm}$ when dissolved in water with $\mathrm{pH}$ greater than 5.5. Titration with $\mathrm{HCl}$ led to significant changes in the visible absorption spectra with maintenance of isosbestic points. Representative data for $\left[\mathrm{Ru}(\mathrm{dtb})_{2}(\mathrm{dcb})\right]^{2+}$ and $[\mathrm{Ru}-$ $\left.(\mathrm{btfmb})_{2}(\mathrm{dcb})\right]^{2+}$ are given in Figure 3 . At $\mathrm{pH}$ values less than 3, $\left[\mathrm{Ru}^{\mathrm{II}}(\mathrm{btfmb})_{2}(\mathrm{dcb})\right]^{2+}$ displayed sharper and more intense absorption than in alkaline solution while $\left[\mathrm{Ru}^{\mathrm{II}}(\mathrm{dtb})_{2}(\mathrm{dcb})\right]^{2+}$ exhibited two distinct MLCT absorption bands, with maxima at
430 and $480 \mathrm{~nm}$, and a decreased absorptivity at $450 \mathrm{~nm}$. Titration of the mcb compounds enabled the spectroscopic identification of the intermediate, monoprotonated, state of all the $\mathrm{dcb}$ compounds, $\left[\mathrm{RuL}_{2}(\mathrm{dcb})\right]^{1+}$, via direct spectral comparison, Figure S1 (Supporting Information). Shown in black in Figure 3 are the absorption spectra of the monoprotonated compounds that have absorption spectra that are very similar to that of the mcb compounds. The absorbance for all compounds was $\mathrm{pH}$ independent over the ranges $\mathrm{pH}$ 5-12 and $\mathrm{pH} 1-2$.

Visible light excitation resulted in room temperature photoluminescence (PL) for all the compounds. Under basic conditions, $\left[\mathrm{Ru}^{\mathrm{II}}(\mathrm{btfmb})_{2}(\mathrm{dcb})\right]^{2+*}$ exhibited PL centered at $648 \mathrm{~nm}$ that blue-shifted to $633 \mathrm{~nm}$ in acidic solution; an energy increase of approximately $370 \mathrm{~cm}^{-1}$. The $\mathrm{PL}$ from $\left[\mathrm{Ru}^{\mathrm{II}}(\mathrm{dtb})_{2}(\mathrm{dcb})\right]^{2+*}$ dissolved in basic aqueous solution displayed a maximum at $653 \mathrm{~nm}$ that red-shifted to $693 \mathrm{~nm}$ under acidic conditions; an approximately $950 \mathrm{~cm}^{-1}$ energetic shift. The PL spectra measured under highly acidic and basic conditions were assigned as the protonated and deprotonated form of the compounds, respectively. For all compounds the PL intensity increased as the spectra shifted toward shorter wavelength, Table 2. Titration of the mcb compounds afforded knowledge of the PL spectra for the monoprotonated states of the dcb compounds, Figure S1. The corrected PL spectra were modeled with a Franck-Condon line-shape analysis that afforded the $\mathrm{E}_{00}$ value as has been previously reported. ${ }^{62,63}$

The PL quantum yields $\phi_{\mathrm{PL}}$, expressed as a percentage ranged from $0.33 \%$ to $5.23 \%$, Table 2 . Pulsed light excitation of the compounds in aqueous solutions with $\mathrm{pH}<2$ or $\mathrm{pH}>5.5$ yielded excited states that decayed to the ground state by a first-order kinetic process with characteristic excited state lifetimes, $\tau_{\mathrm{obs}}=1$ / $k_{\text {obs }}$. Knowledge of $\phi_{\mathrm{PL}}$ and $k_{\mathrm{obs}}$ enabled calculation of the radiative, $k_{\mathrm{r}}$, and nonradiative, $k_{\mathrm{nr}}$, decay rate constants, eq 3 .

$$
k_{\mathrm{r}}=\eta \phi_{\mathrm{PL}} k_{\mathrm{obs}} ; \quad k_{\mathrm{nr}}=k_{\mathrm{obs}}-k_{\mathrm{r}}
$$

where $\eta$ is the intersystem crossing quantum yield and is assumed to be 1 as found for $\left[\mathrm{Ru}(\mathrm{bpy})_{3}\right]^{2+} \cdot 51,64,65 \mathrm{~A}$ plot of the nonradiative rate constants versus the $E_{00}$ energy for all compounds was found to be linear as predicted by the energy gap law, Figure S2. The photophysical parameters are given in Table 2. At intermediate $\mathrm{pH}$ values where an excited state acidbase equilibrium was relevant for the photobasic compounds, PL
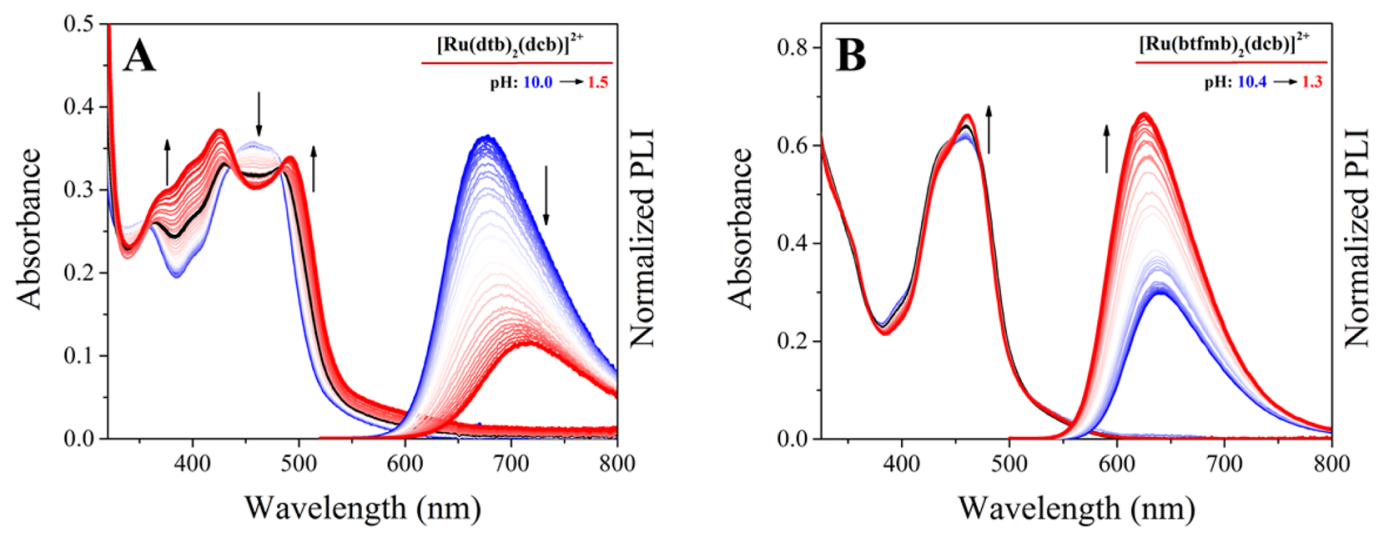

Figure 3. Visible absorption and photoluminescence spectra of $\left[\mathrm{Ru}(\mathrm{dtb})_{2}(\mathrm{dcb})\right]^{2+}(\mathrm{A})$ and $\left[\mathrm{Ru}(\mathrm{btfmb})_{2}(\mathrm{dcb})\right]^{2+}(\mathrm{B})$ in aqueous solution over the indicated $\mathrm{pH}$ range. The arrows indicate the spectral changes measured as the $\mathrm{pH}$ was decreased by titration with $\mathrm{HCl}$. The spectra in bold blue are assigned to the fully deprotonated carboxylate compounds, while the bold black are the monoprotonated compound, and the bold red are assigned to the diprotonated carboxylic acid form of the compounds. 
Table 2. Photophysical Properties in Acidic and Basic Aqueous Solution

\begin{tabular}{|c|c|c|c|c|c|c|c|}
\hline compd & $\mathrm{pH}^{a}$ & $\operatorname{MLCT}(\mathrm{nm})^{b}$ & $\mathrm{PL}_{\max }(\mathrm{nm})^{b}$ & $\phi_{\mathrm{PL}}(\%)^{c}$ & $\tau(\mathrm{ns})^{c d}$ & $k_{\mathrm{r}}\left(\mathrm{s}^{-1}\right)^{e}$ & $k_{\mathrm{nr}}\left(\mathrm{s}^{-1}\right)^{f}$ \\
\hline \multirow[t]{2}{*}[\mathrm{Ru}(\mathrm{bpy})_{2}(\mathrm{mcb})]{$^{2+}$} & 6.3 & 472 & 679 & 2.1 & 340 & $6.2 \times 10^{4}$ & $2.9 \times 10^{6}$ \\
\hline & 1.6 & 479 & 694 & 1.5 & 270 & $5.6 \times 10^{4}$ & $3.6 \times 10^{6}$ \\
\hline \multirow[t]{2}{*}[\mathrm{Ru}(\mathrm{dtb})_{2}(\mathrm{mcb})]{$^{2+}$} & 7.3 & 483 & 701 & 0.53 & 210 & $2.5 \times 10^{4}$ & $4.8 \times 10^{6}$ \\
\hline & 1.6 & 593 & 720 & 0.38 & 150 & $2.5 \times 10^{4}$ & $6.6 \times 10^{6}$ \\
\hline \multirow[t]{2}{*}[\mathrm{Ru}(\mathrm{btfmb})_{2}(\mathrm{mcb})]{$^{2+}$} & 4.5 & 459 & 640 & 3.9 & 550 & $7.1 \times 10^{4}$ & $1.7 \times 10^{6}$ \\
\hline & 1.5 & 460 & 635 & 5.9 & 670 & $7.7 \times 10^{4}$ & $1.4 \times 10^{6}$ \\
\hline$\left[\mathrm{Ru}(\mathrm{bpy})_{2}(\mathrm{dcb})\right]^{2+}$ & 1.0 & 481 & 693 & 1.5 & 260 & $5.7 \times 10^{4}$ & $3.8 \times 10^{6}$ \\
\hline \multirow[t]{2}{*}[\mathrm{Ru}(\mathrm{dtb})_{2}(\mathrm{dcb})]{$^{2+}$} & 10.0 & 455 & 676 & 1.3 & 300 & $4.2 \times 10^{4}$ & $3.3 \times 10^{6}$ \\
\hline & 1.5 & 493 & 715 & 0.33 & 140 & $2.4 \times 10^{4}$ & $7.1 \times 10^{6}$ \\
\hline \multirow[t]{2}{*}[\mathrm{Ru}(\mathrm{btfmb})_{2}(\mathrm{dcb})]{$^{2+}$} & 10.5 & 460 & 648 & 2.6 & 440 & $5.8 \times 10^{4}$ & $2.2 \times 10^{6}$ \\
\hline & 0.4 & 460 & 633 & 5.2 & 690 & $7.6 \times 10^{4}$ & $1.4 \times 10^{6}$ \\
\hline
\end{tabular}

${ }^{a}$ Aqueous solutions. ${ }^{b}$ Wavelengths are $\pm 2 \mathrm{~nm} .{ }^{c} \mathrm{PL}$ quantum yields measured using $\left[\mathrm{Ru}(\mathrm{bpy})_{3}\right] \mathrm{Cl}_{2}$ in water as a standard $\left(\phi_{\mathrm{PL}}=0.042\right)$ with errors of $\pm 10 \% .{ }^{59}{ }^{d}$ Lifetimes are $\pm 5 \%$. ${ }^{e} k_{\mathrm{r}}=\eta \phi_{\mathrm{PL}} k_{\mathrm{obs} \cdot}{ }^{\circ} k_{\mathrm{nr}}=k_{\mathrm{obs}}-k_{\mathrm{r}}$. All measurements were obtained at $+20{ }^{\circ} \mathrm{C} \pm 2{ }^{\circ} \mathrm{C}$.

Table 3. Ground and Excited State $\mathrm{p} K_{\mathrm{a}}$ for All Compounds Containing the mcb Ligand

\begin{tabular}{|c|c|c|c|c|c|}
\hline \multirow[b]{2}{*}{ compd } & \multicolumn{2}{|c|}{$\mathrm{p} K_{\mathrm{a}}$} & \multicolumn{3}{|c|}{$\mathrm{p} K_{\mathrm{a}}^{*}$} \\
\hline & inflection point ${ }^{a}$ & spectral modeling $^{b}$ & Förster cycle $^{c}$ & lifetime $^{d}$ & spectral modeling $^{e}$ \\
\hline$\left[\mathrm{Ru}(\mathrm{bpy})_{2}(\mathrm{mcb})\right]^{2+}$ & 2.31 & 2.31 & 3.08 & $2.77^{f}$ & 2.95 \\
\hline$\left[\mathrm{Ru}(\mathrm{dtb})_{2}(\mathrm{mcb})\right]^{2+}$ & 2.51 & 2.38 & 3.23 & $3.18^{f}$ & 3.35 \\
\hline$\left[\mathrm{Ru}(\mathrm{btfmb})_{2}(\mathrm{mcb})\right]^{2+}$ & 2.25 & 2.24 & 1.88 & 2.08 & 2.02 \\
\hline
\end{tabular}

${ }^{a}$ Calculated from the inflection point of the spectrophotometric titration curve, Figure S3. ${ }^{b}$ Calculated from spectral modeling of the UV-vis absorption data, Figure $4 .{ }^{c}$ Calculated with eq $8 .{ }^{d}$ Calculated with eq $7 .{ }^{e}$ Calculated from the spectral modeling of PL titration data. ${ }^{f}$ Assumptions for lifetime correction were not justified for these excited states, see Discussion.

Table 4. Ground and Excited State $\mathrm{p} K_{\mathrm{a}}$ for All Compounds Containing the dcb Ligand

\begin{tabular}{|c|c|c|c|c|c|c|c|c|c|}
\hline \multirow[b]{2}{*}{ compd } & \multirow{2}{*}{$\frac{\text { inflection point }}{\mathrm{p} K_{\mathrm{a}}{ }^{a}}$} & \multicolumn{2}{|c|}{ spectral modeling } & \multicolumn{2}{|c|}{ Förster cycle } & \multicolumn{2}{|c|}{ lifetime } & \multicolumn{2}{|c|}{ spectral modeling } \\
\hline & & $\mathrm{p} K_{\mathrm{a} 1}^{b}$ & $\mathrm{pK}_{\mathrm{a} 2}^{b}$ & $\mathrm{p} K_{\mathrm{al}} *^{c}$ & $\mathrm{p} K_{\mathrm{a} 2} *^{c}$ & $\mathrm{p} K_{\mathrm{al}} *^{d}$ & $\mathrm{p} K_{\mathrm{a} 2} *^{d}$ & $\mathrm{p} K_{\mathrm{a} 1} *^{e}$ & $\mathrm{p} K_{\mathrm{a} 2} *^{e}$ \\
\hline$\left[\mathrm{Ru}(\mathrm{bpy})_{2}(\mathrm{dcb})\right]^{2+}$ & 2.55 & 2.01 & 2.83 & 2.78 & 4.07 & $2.58^{f}$ & $3.72^{f}$ & 2.70 & 3.90 \\
\hline$\left[\mathrm{Ru}(\mathrm{dtb})_{2}(\mathrm{dcb})\right]^{2+}$ & 2.91 & 2.15 & 3.15 & 3.00 & 4.32 & $2.65^{f}$ & $3.93^{f}$ & 2.94 & 4.06 \\
\hline$\left[\mathrm{Ru}(\mathrm{btfmb})_{2}(\mathrm{dcb})\right]^{2+}$ & 2.89 & 2.20 & 3.15 & 1.84 & 2.72 & 1.48 & 2.19 & 1.43 & 2.15 \\
\hline
\end{tabular}

${ }^{a}$ Calculated from the inflection point of the raw spectrophotometric titration curve, Figure S4. ${ }^{b}$ Calculated from spectral modeling of the UV-vis absorption data, Figure 5. ${ }^{c}$ Calculated with eq $8 .{ }^{d}$ Calculated with eq $7 .{ }^{e}$ Calculated from spectral modeling of the PL data and appropriated corrections to the PL quantum yield. ${ }^{f}$ Assumptions for lifetime correction were not justified for these excited states, see Discussion.
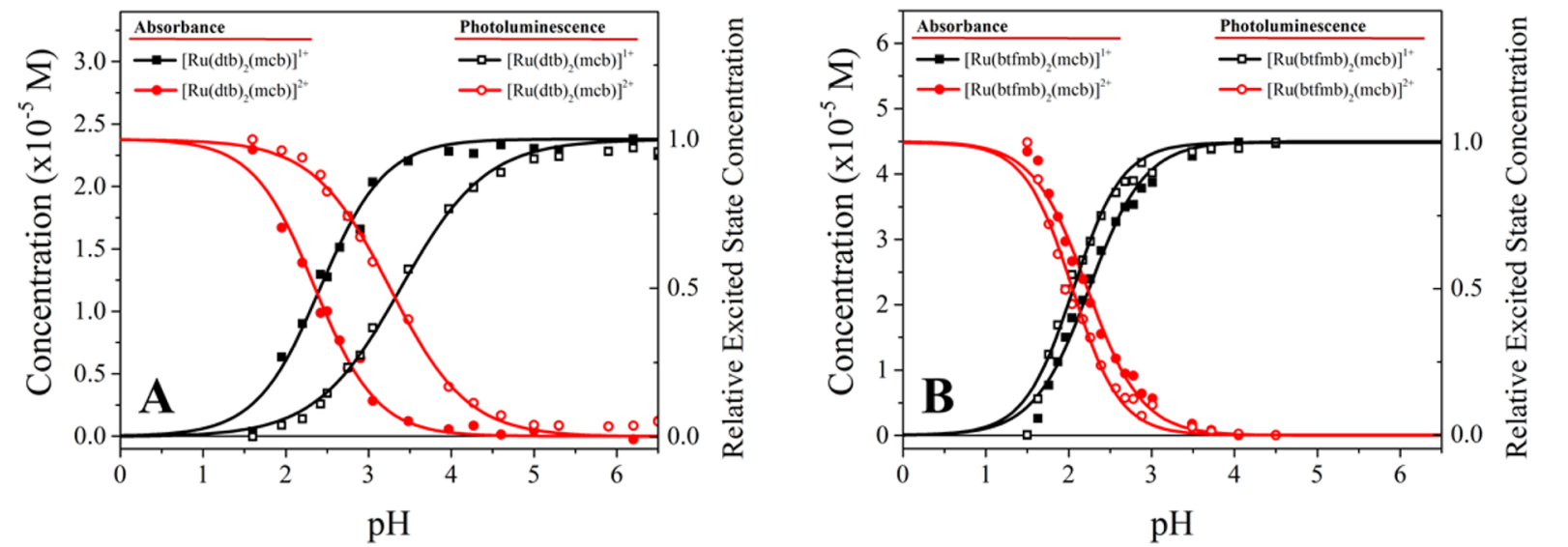

Figure 4. Spectral modeling curves of $\left[\mathrm{Ru}(\mathrm{dtb})_{2}(\mathrm{mcb})\right]^{2+}(\mathrm{A})$ and $\left[\mathrm{Ru}(\mathrm{btfmb})_{2}(\mathrm{mcb})\right]^{2+}(\mathrm{B})$ reporting on the ground state concentration $(\mathrm{solid}$ symbols) and relative excited state concentration (open symbols) changes of the indicated protonation states as a function of the $\mathrm{pH}$.

decays monitored at all observation wavelengths were no longer single exponential and were instead well described by a biexponential kinetic model.

The ground-state $\mathrm{p} K_{\mathrm{a}}$ 's were determined from inflection points in the spectrophotometric titration data monitored at single wavelengths, Figures S3 and S4, as well as by full wavelength spectral modeling since the $\mathrm{pH}$ value where equal concentrations of the acid and conjugated base defines the $\mathrm{p} K_{\mathrm{a}}$ Tables 3 and 4. Representative spectral analysis data for monocarboxylic acid compounds and for dicarboxylic acid 

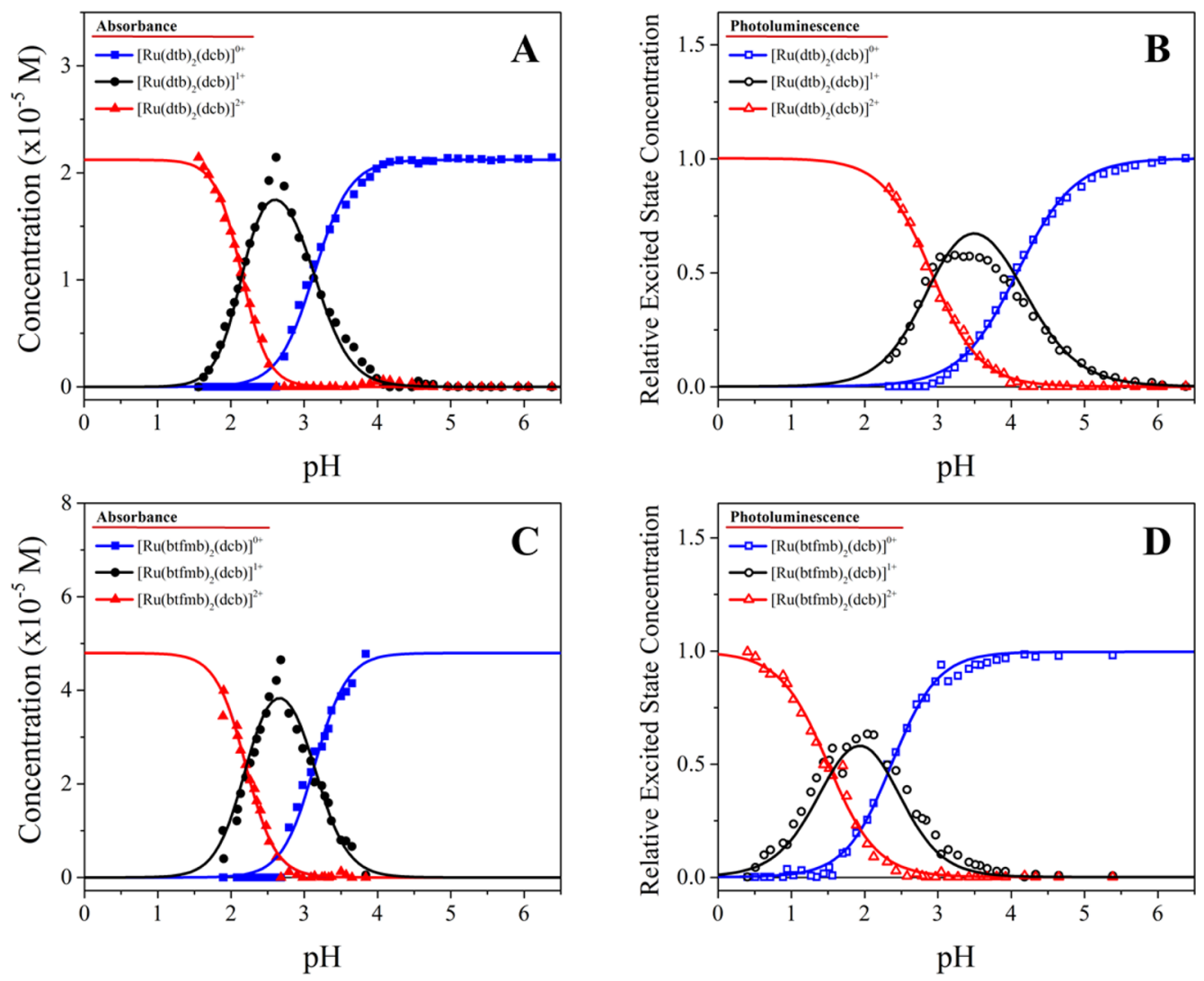

Figure 5. Spectral modeling curves of $\left[\mathrm{Ru}(\mathrm{dtb})_{2}(\mathrm{dcb})\right]^{2+}(\mathrm{A}, \mathrm{B})$ and $\left[\mathrm{Ru}(\mathrm{btfmb})_{2}(\mathrm{mcb})\right]^{2+}(\mathrm{C}, \mathrm{D})$ reporting on the ground state concentration $($ solid symbols) and relative excited state concentration (open symbols) of the indicated protonation states as a function of the $\mathrm{pH}$.
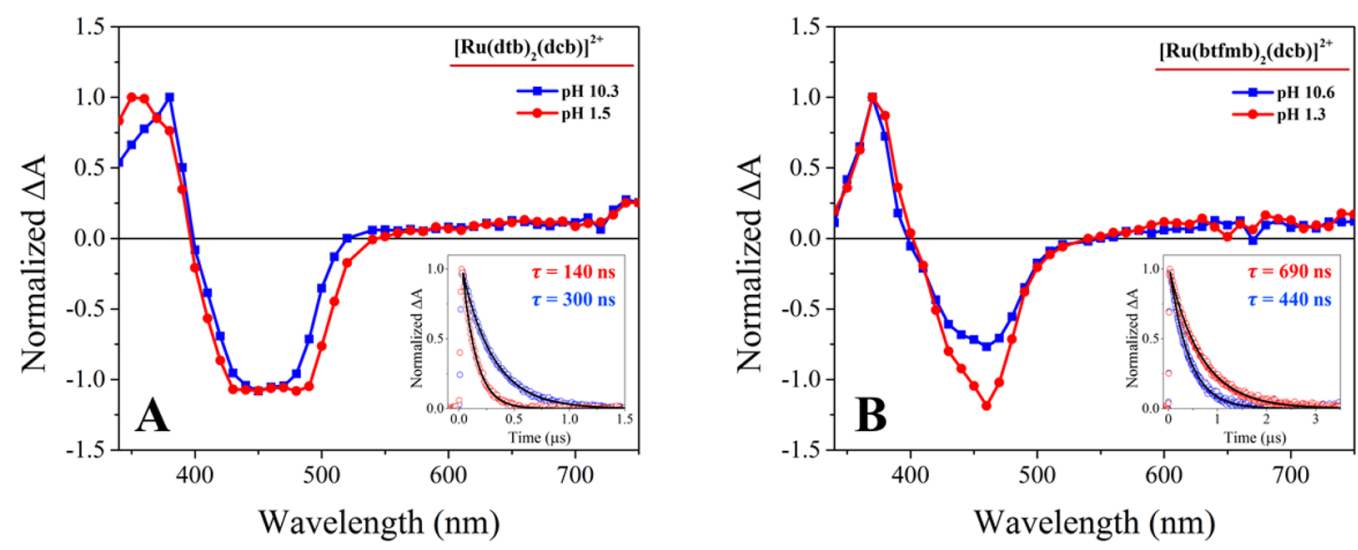

Figure 6. Transient absorption spectra measured $25 \mathrm{~ns}$ after pulsed $532 \mathrm{~nm}$ light excitation of $(\mathrm{A})\left[\mathrm{Ru}(\mathrm{dtb})_{2}(\mathrm{dcb})\right]^{2+}$ and $(\mathrm{B})\left[\mathrm{Ru}(\mathrm{btfmb})_{2}(\mathrm{dcb})\right]^{2+}$ under the indicated basic (blue) and acid (red) conditions. The insets display single wavelength kinetics measured at $450 \mathrm{~nm}$ at the indicated $\mathrm{pH}$ conditions with overlaid fits to a first-order kinetic model.

compounds are given in Figures 4 and 5, respectively. The presence of the monoprotonated compound was clearly identified in the spectral analyses of the dcb compounds.

Figures 4 and 5 also display titration data where the integrated PL intensity was quantified by a full spectral analysis. Care was taken to excite at the ground state isosbestic points so that the excited state concentration remained constant over the entire $\mathrm{pH}$ range. The measured $\mathrm{PL}$ spectra at any given $\mathrm{pH}$ were deconvoluted into the contributions from each emitting species that were then integrated and divided by the known quantum yields. This provided the relative excited state concentrations of each species at each $\mathrm{pH}$. The $\mathrm{pH}$ where the concentrations of the excited acid and conjugate base were equal was defined as the $\mathrm{p} K_{\mathrm{a}}^{*}$ value. Given in the Supporting Information is the more common approach of using the PL intensity directly, termed the raw PLI. The difficulty with this approach is twofold. First, for these compounds, the PL spectra of all species overlap in energy. This was particularly problematic for the dcb containing compounds where three different species could contribute to the measured intensity at any given wavelength. Second, the PL intensity does not report on concentrations and the inflection points do not yield the $\mathrm{p} K_{\mathrm{a}}^{*}$ values as is described in the Discussion.

Transient absorption difference spectra measured $25 \mathrm{~ns}$ after pulsed $532 \mathrm{~nm}$ laser excitation of $\left[\mathrm{Ru}^{\mathrm{II}}(\mathrm{btfmb})_{2}(\mathrm{dcb})\right]^{2+}$ or $\left[\mathrm{Ru}{ }^{\mathrm{II}}(\mathrm{dtb})_{2}(\mathrm{dcb})\right]^{2+}$ are shown in Figure 6. Clean isosbestic 

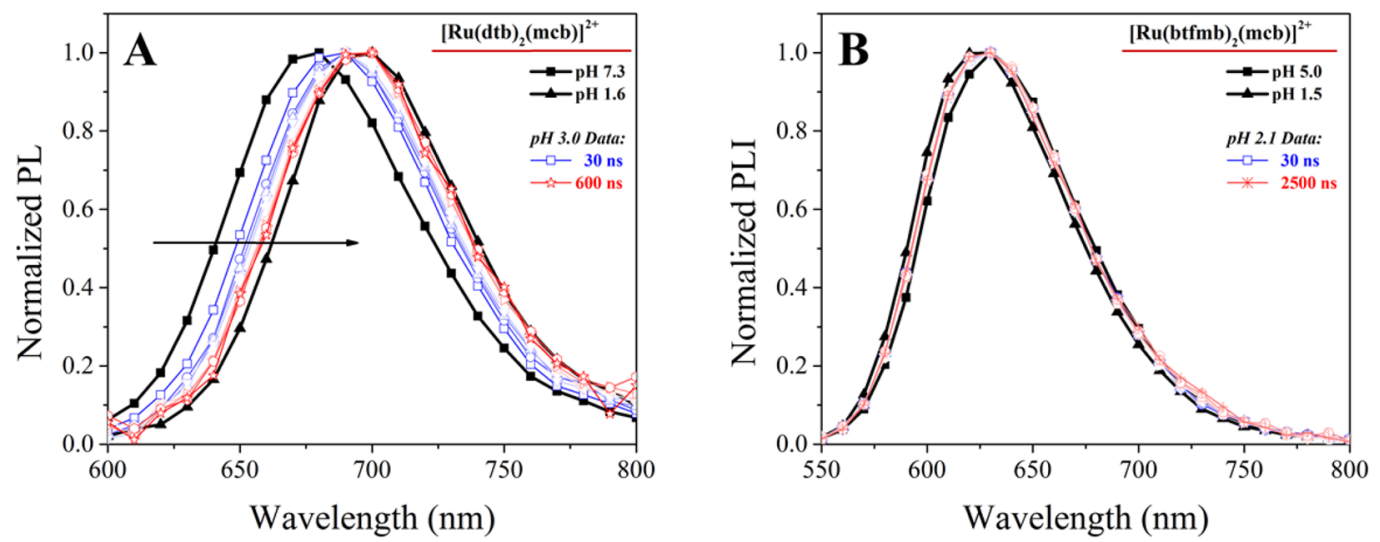

Figure 7. Transient photoluminescence spectra obtained $30 \mathrm{~ns}$ (blue squares) and longer (blue to red) time delays after pulsed $532 \mathrm{~nm}$ laser excitation of $\left[\mathrm{Ru}(\mathrm{dtb})_{2}(\mathrm{mcb})\right]^{2+}(\mathrm{A})$ and $\left[\mathrm{Ru}(\mathrm{btfmb})_{2}(\mathrm{mcb})\right]^{2+}(\mathrm{B})$ at the indicated $\mathrm{pH}$ value. The time independent spectra of the fully deprotonated and protonated forms obtained after pulsed laser excitation are given for reference under basic (black, square) and acidic (black, up triangle) conditions.
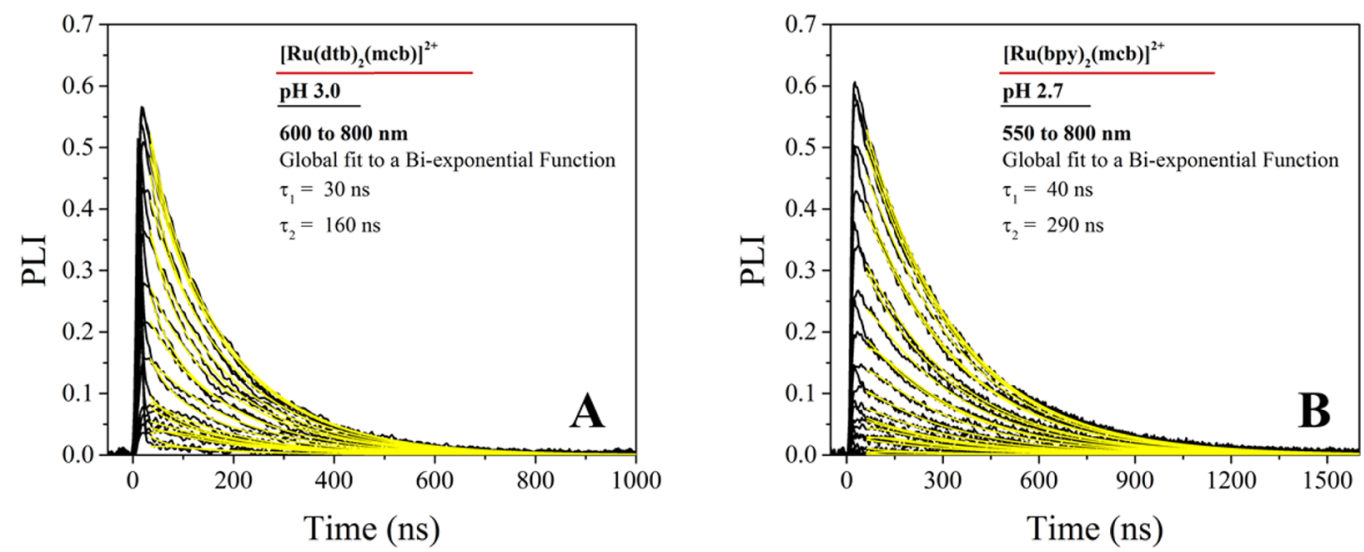

Figure 8. Biexponential global fit of the time-resolved photoluminescence measured as a function of the monitoring wavelength at the indicated $\mathrm{pH}$ values with the $\tau_{1}$ and $\tau_{2}$ values derived from the coupled system analysis for $(\mathrm{A})\left[\mathrm{Ru}(\mathrm{dtb})_{2}(\mathrm{mcb})\right]^{2+*}$ and $(\mathrm{B})\left[\mathrm{Ru}(\mathrm{bpy})_{2}(\mathrm{mcb})\right]^{2+*}$.

points were observed around 400 and $530 \mathrm{~nm}$ for all compounds studied at $\mathrm{pH}$ values less than two or greater than five. The transient absorption spectra were superposable with respect to time, behavior consistent with the formation of a single excited state. The spectra displayed a positive absorption feature below $400 \mathrm{~nm}$ that was assigned as a ligand-centered ${ }^{3} \pi \rightarrow{ }^{3} \pi^{*}$ transition. Sharp transient absorption features with maxima near $370 \mathrm{~nm}$ were observed after pulsed light excitation of both the diprotonated and fully deprotonated forms of $[\mathrm{Ru}$ $\left.(\mathrm{btfmb})_{2}(\mathrm{dcb})\right]^{2+*}$. In contrast, the normalized spectra of $\left[\mathrm{Ru}(\mathrm{dtb})_{2}(\mathrm{dcb})\right]^{2+*}$ revealed an absorption maximum at 380 $\mathrm{nm}$ for the diprotonated compound and at $350 \mathrm{~nm}$ for the fully deprotonated form. The transient bleach minimum was observed at $450 \mathrm{~nm}$ for both forms of $\left[\mathrm{Ru}(\mathrm{dtb})_{2}(\mathrm{dcb})\right]^{2+*}$, although the bleach was broader for the protonated form compared to the deprotonated form, consistent with the ground state absorption spectra. Control experiments with $[\mathrm{Ru}(\mathrm{bpy})]_{3}{ }^{2+}$ revealed a $\mathrm{pH}$ independent absorption band at $370 \mathrm{~nm}$ and a bleach at $450 \mathrm{~nm}$. The first-order excited state relaxation kinetics were observation wavelength independent with abstracted rate constants in excellent agreement with those measured independently by time-resolved photoluminescence.

Photoluminescence spectra of $\left[\mathrm{Ru}(\mathrm{dtb})_{2}(\mathrm{mcb})\right]^{2+*}$ measured $25 \mathrm{~ns}$ after pulsed laser excitation, are shown in Figure 7A. The normalized photoluminescence spectra at $\mathrm{pH} 1.6$ and 7.3 were superposable with time. The spectra obtained at $\mathrm{pH}$ of 3.0 were not superposable and exhibited a significant red-shift with increased time. Note that the PL maxima were not the same as that seen in Table 2 and Figure 2, as they were measured transiently on an apparatus that had not been spectrally corrected. Similar time dependent red shifts in the PL spectra were measured for $\left[\mathrm{Ru}(\mathrm{dtb})_{2}(\mathrm{dcb})\right]^{2+*},\left[\mathrm{Ru}(\mathrm{bpy})_{2}(\mathrm{dcb})\right]^{2+*}$, and $\left[\mathrm{Ru}(\mathrm{bpy})_{2}(\mathrm{mcb})\right]^{2+*}$ at intermediate $\mathrm{pH}$ values where excited state acid-base equilibria was expected. In contrast, the $\mathrm{PL}$ spectra of the compounds that contained the btfmb ligand were time independent at all $\mathrm{pH}$ values measured, even with streak-camera detection that afforded 300 ps time resolution. Representative data for $\left[\mathrm{Ru}(\mathrm{btfmb})_{2}(\mathrm{dcb})\right]^{2+*}$ is given in Figure 7B.

Excited state relaxation was found to be nonexponential for the photobasic compounds at $\mathrm{pH}$ values where an excited state acidbase equilibrium was expected. Instead, the data was well described by a sum of two first-order rate constants. Shown in Figure 8 are representative PL decays monitored from 600 to 800 $\mathrm{nm}$ with overlaid fits to a biexponential kinetic model. This analysis revealed two lifetimes of 40 and $290 \mathrm{~ns}$ for [Ru$\left.(\mathrm{bpy})_{2}(\mathrm{mcb})\right]^{2+}$ and 30 and $160 \mathrm{~ns}$ for $\left[\mathrm{Ru}(\mathrm{dtb})_{2}(\mathrm{mcb})\right]^{2+}$, that were independent of the monitoring wavelength.

\section{DISCUSSION}

Thorough spectroscopic measurements and kinetic analysis revealed that four of the six ruthenium polypyridyl compounds investigated were less acidic in the excited state, i.e. photobases, while the remaining two were more acidic, that is, photoacids. 
This is unprecedented behavior as decades of research has taught that the identity of the ionizable group regulates excited-state acid-base behavior: all previous organic dyes with conjugated carboxylate groups were identified to be photobases. ${ }^{66-69}$ Yet among these closely related compounds this clearly was not the case. The excited state studies reported provide insights into the origins of this new behavior and suggest means by which it can be further optimized for practical and fundamental applications. Also reported is the first quantification of excited state proton transfer in transition metal compounds that provide the kinetic rate constants that control excited state acid-base chemistry and $\mathrm{p} K_{\mathrm{a}}{ }^{*}$ values. The photophysical behavior of the compounds is described below followed by the thermodynamics and kinetics.

Photophysical Properties. The photophysical properties reported are characteristic of compounds with low-lying metalto-ligand charge-transfer (MLCT) excited states that are formally characterized as an oxidized metal center and an electron localized on a single diimine ligand. ${ }^{70-74}$ For heteroleptic tris-chelate compounds, the excited state localizes on the most easily reduced ligand on time scales relevant to these studies. $^{75-81}$ Nanosecond transient absorption data were consistent with this assertion and the formation of thermally equilibrated MLCT states as shown in eqs 4-6.

$$
\begin{aligned}
& {\left[\mathrm{Ru}^{\mathrm{II}}(\mathrm{bpy})_{2}(\mathrm{dcb})\right]^{2+}+h v \rightarrow\left[\mathrm{Ru}^{\mathrm{III}}(\mathrm{bpy})_{2}\left(\mathrm{dcb}^{-}\right)\right]^{2+*}} \\
& {\left[\mathrm{Ru}^{\mathrm{II}}(\mathrm{dtb})_{2}(\mathrm{dcb})\right]^{2+}+h v \rightarrow\left[\mathrm{Ru}^{\mathrm{III}}(\mathrm{dtb})_{2}\left(\mathrm{dcb}^{-}\right)\right]^{2+*}} \\
& {\left[\mathrm{Ru}^{\mathrm{II}}(\mathrm{btfmb})_{2}(\mathrm{dcb})\right]^{2+}+h v} \\
& \quad \rightarrow\left[\mathrm{Ru}^{\mathrm{III}}(\mathrm{btfmb})(\mathrm{btfmb})(\mathrm{dcb})\right]^{2+*}
\end{aligned}
$$

Assignments based solely on electronic spectra are not as definitive as those based on time-resolved resonance Raman measurements that provide a direct fingerprint through the vibrational spectrum of the luminescent excited state. ${ }^{75-81}$ Nevertheless, the UV absorption band of the excited states were well resolved and characteristic of the reduced ligand present in the excited state, providing compelling evidence for these assignments. ${ }^{82}$ In addition, Hammett parameters predict that the electron-withdrawing influence of the $4,4^{\prime}$-substituents should increase in the order tert-butyl $(\sigma=-0.20)<\mathrm{H}(\sigma=0)<\mathrm{COOH}$ $(\sigma=0.45)<\mathrm{CF}_{3}(\sigma=0.54),{ }^{82}$ consistent with this interpretation. The ethyl ester group has a Hammett parameter identical to that of the carboxylic acid, ${ }^{82}$ so eqs $4-6$ also apply to the monocarboxylic acid (mcb) compounds.

The influence of the carboxylate-carboxylic acid equilibrium on the energy gap is of particular interest to this manuscript. For the excited states localized on the dcb or mcb ligand, the more electron withdrawing carboxylic acid stabilizes the excited state relative to the carboxylate consistent with the blue (hypsochromic) shift as the $\mathrm{pH}$ was raised. For the excited states localized on the btfmb ligand, radiative decay did not formally involve the dcb or mcb ligand and the observed red (bathochromic) shift with increased $\mathrm{pH}$ emanated from a $\mathrm{pH}$ induced shift in the ground state $\mathrm{Ru}^{\mathrm{III} / \mathrm{II}}$ potential. The withdrawing nature of the carboxylic acids made oxidation of the metal center more difficult relative to the conjugate carboxylate base. We note that scholarly texts ${ }^{83}$ and classical studies ${ }^{84}$ have shown that the electron withdrawing nature of a carboxylic acid groups is best understood as a field effect, rather than an inductive effect, that is directly transmitted through space rather than along bonds. In practice, it is difficult to separate these two and herein the term "inductive effect" is utilized to refer to their combined action.
The excited state lifetimes and quantum yields were dictated by the nonradiative rate constants that were about 2 orders of magnitude larger than the radiative rate constants. The $k_{\mathrm{nr}}$ values increase exponentially with the energy separation between the ground and excited state in accord with the energy gap law. ${ }^{63,85-87}$ Interestingly, at a given energy gap an excited state localized on a dcb (or mcb) ligand had a significantly smaller $k_{\mathrm{nr}}$ value than did one localized on a btfmb ligand. For example, a compound that emits red light at $650 \mathrm{~nm}\left(\sim 15400 \mathrm{~cm}^{-1}\right)$ has about twice as long an excited state lifetime when localized on a $\mathrm{dcb}$ (or $\mathrm{mcb}$ ) ligand. This is attributed to a resonance (i.e., mesomeric) effect where conjugation between the carboxylic acid and the pyridine ring result in greater delocalization of the excited state and a longer lifetime. ${ }^{83}$ The distortion angle between carboxylic acid groups and the pyridine ring was $<10^{\circ}$ in solid state $\left[\mathrm{Ru}(\mathrm{bpy})_{2}(\mathrm{mcb})\right]^{2+}$, where intermolecular $\pi-\pi$ interactions appear to dominate crystal packing. The excited state structure in aqueous solution is expected to differ. There is in fact compelling evidence for MLCT excited state delocalization onto aromatic substituents in these same 4 - and $4^{\prime}$-positions of bipyridine in a manner similar to that envisioned here. ${ }^{63,88,89}$

Thermodynamics. Single inflection and isosbestic points were observed in the spectrophotometric titration data even though two were expected for the compounds with a dcb ligand. Such behavior has previously been reported for the parent compound $\left[\mathrm{Ru}^{\mathrm{II}}(\mathrm{bpy})_{2}(\mathrm{dcb})\right]^{2+1,27,34,90}$ leading to a considerable uncertainty in the true $\mathrm{p} K_{\mathrm{a}}$ values. To better understand this chemistry, the mcb ligand that contains one ethyl ester and one carboxylic acid group in the 4 - and $4^{\prime}$-positions of bipyridine was synthesized. Indeed the visible absorption spectra of the deprotonated form of compounds with the mcb ligand enabled the monoprotonated $\mathrm{dcb}$ compounds absorption spectra to be identified. This spectrum, when combined with the spectra of the diprotonated and fully deprotonated compounds, enabled full spectral simulation of all the titration data that in turn provided accurate determinations of the $\mathrm{p} K_{\mathrm{a}}$ values. It is of interest to briefly contrast the values for $\left[\mathrm{Ru}^{\mathrm{II}}(\mathrm{bpy})_{2}(\mathrm{dcb})\right]^{2+}$ with those previously reported in the literature, Table 5.

\section{Table 5. Ground and Excited State $\mathrm{p} K_{\mathrm{a}}$ Values for} $\left[\mathbf{R u}(\mathrm{bpy})_{2}(\mathrm{dcb})\right]^{2+}$

\begin{tabular}{cccccc} 
compd & $\mathrm{p} K_{\mathrm{a} 1}$ & $\mathrm{p} K_{\mathrm{a} 2}$ & $\mathrm{p} K_{\mathrm{a} 1}{ }^{*}$ & $\mathrm{p} K_{\mathrm{a} 2}{ }^{*}$ & ref \\
{$\left[\mathrm{Ru}(\mathrm{bpy})_{2}(\mathrm{dcb})\right]^{2+}$} & 5.50 & 5.50 & 8.50 & 8.50 & 27 \\
{$\left[\mathrm{Ru}(\mathrm{bpy})_{2}(\mathrm{dcb})\right]^{2+}$} & 1.75 & 2.80 & & & 48 \\
{$\left[\mathrm{Ru}(\mathrm{bpy})_{2}(\mathrm{dcb})\right]^{2+}$} & 1.85 & 2.90 & 3.60 & 4.50 & 32 \\
{$\left[\mathrm{Ru}(\mathrm{bpy})_{2}(\mathrm{dcb})\right]^{2+}$} & 1.75 & 2.85 & 4.25 & & 31 \\
{$\left[\mathrm{Ru}(\mathrm{bpy})_{2}(\mathrm{dcb})\right]^{2+}$} & 0.5 & 2.65 & $<0.2$ & 4.10 & 33 \\
{$\left[\mathrm{Ru}(\mathrm{bpy})_{2}(\mathrm{dcb})\right]^{2+}$} & 2.01 & 2.83 & 2.58 & 3.72 & this work \\
\hline
\end{tabular}

The lack of isosbestic points in the acid base titration of $\left[\mathrm{Ru}^{\mathrm{II}}(\mathrm{bpy})_{2}(\mathrm{dcb})\right]^{2+}$ led Giordano et al. to model the equilibria as the simultaneous loss of both protons. ${ }^{27}$ This analysis resulted in about a factor of 2 error in the reported $\mathrm{p} K_{\mathrm{a}}$ values and the incorrect conclusion that the two carboxylic acids had the same ionization constants. Through careful titration studies, Ferguson et al., ${ }^{48}$ Lay and Sasse, ${ }^{32}$ and Nazeeruddin and Kalyanasundar$\mathrm{am}^{31}$ were able to identify both equilibrium processes; the $\mathrm{p} K_{\mathrm{a} 2}$ values reported were in good agreement, while the $\mathrm{p} K_{\mathrm{a} 1}$ values were $\sim 0.25-0.15 \mathrm{p} K_{\mathrm{a}}$ units lower than that reported here, behavior suspected to result from single wavelength rather than full spectral analysis. Shimidzu et al. observed an isosbestic point in very acidic solutions, the nature of which remains unknown. ${ }^{33}$ 


\section{$\underline{\text { Single Acid-Base Equilibrium }}$}

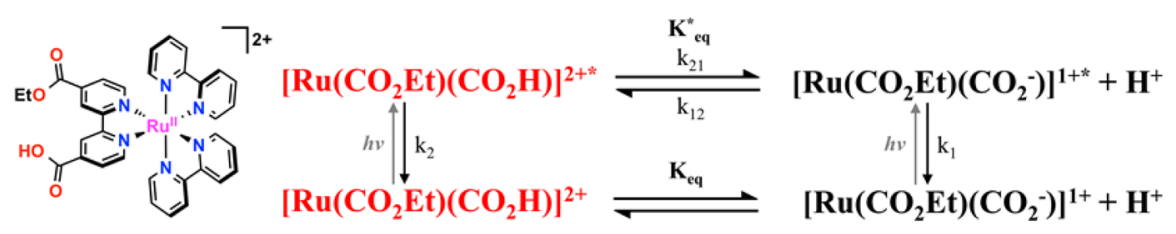

\section{Multiple Acid-Base Equilibrium}
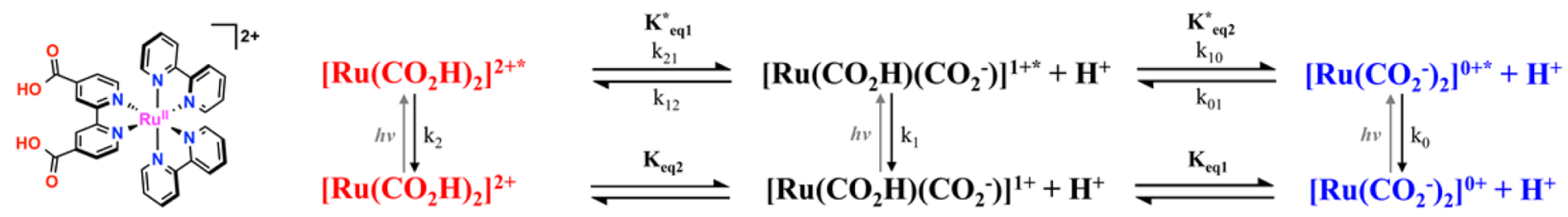

Figure 9. Square scheme for ground and excited state acid-base chemistry of a compound containing one carboxylic acid group (single acid base equilibrium) and two carboxylic acids (multiple acid-base equilibrium).

Photoluminescence (PL) intensity titrations of the dcb containing compounds displayed only a single inflection point when two were expected. Again the mcb compounds were utilized to determine the PL spectra and quantum yields of the monoprotonated dcb-containing compounds that when combined with the other reference spectra enabled the relative excited state concentrations of all the relevant species to be quantified at each $\mathrm{pH}$. A simple PL titration experiment, with light excitation at an isosbestic point, then enabled the direct determination of the $\mathrm{p} K_{\mathrm{a}}{ }^{*}$ values by identification of the $\mathrm{pH}$ where equal concentrations of the excited carboxylic acid and conjugate base were present. To our knowledge, this approach has not been previously proposed and avoids the uncertainties inherent in alternative $\mathrm{p} K_{\mathrm{a}}^{*}$ determinations.

Comparisons of the $\mathrm{p} K_{\mathrm{a}}^{*}$ values of $\left[\mathrm{Ru}^{\mathrm{II}}(\mathrm{bpy})_{2}(\mathrm{dcb})\right]^{2+*}$ with literature reports is revealing in this regard. Previous workers used the $\mathrm{pH}$ at the inflection point $\left(\mathrm{pH}_{\mathrm{i}}\right)$ to determine $\mathrm{p} K_{\mathrm{a}}{ }^{*}$ and were cognizant of the fact that the PL intensity did not report directly on concentration. This was accounted for with eq 7 , where $\tau_{\mathrm{HB}}$ and $\tau_{\mathrm{B}}$ are the lifetimes of the excited acid and conjugate base. ${ }^{1,22,91-95}$

$$
\mathrm{pK}_{\mathrm{a}}^{*}=\mathrm{pH}_{\mathrm{i}}+\log \left(\frac{\tau_{\mathrm{HB}}}{\tau_{\mathrm{B}}}\right)
$$

Derivation of this relation rests on the assumption that an acidbase equilibrium is established in the excited state. ${ }^{1,22}$ However, the kinetic data reported here, and discussed in the following section, reveal that an excited state equilibrium for the photobasic compounds is not achieved until after more than one lifetime. As all previously published data utilized eq 7, the usefulness of these reported values is now realized to be in question. We note that excited state equilibria were established for the photoacids in this study, as described below, validating the use of eq 7 for the btfmb compounds reported here for the first time.

An alternative approach for calculation of $\mathrm{p} K_{\mathrm{a}}{ }^{*}$ values is the Förster method that uses a thermodynamic cycle with the ground state $\mathrm{p} K_{\mathrm{a}}$ and the energy stored in the excited states, eq $8,{ }^{1,22,91,94}$

$$
\mathrm{p} K_{\mathrm{a}}^{*}=\mathrm{p} K_{\mathrm{a}}+\left(\frac{1}{2.303 R T}\right)\left(v_{\mathrm{B}}-v_{\mathrm{HB}}\right)
$$

where $R$ is the gas constant, $T$ is temperature, and $\nu_{\mathrm{B}}$ and $v_{\mathrm{HB}}$ correspond to the $E_{00}$ energy of the deprotonated and protonated compounds, respectively. The large spin-orbit coupling induced by the $\mathrm{Ru}$ center makes spin a poor quantum number and hence considerable uncertainty in the determination of the "true" $E_{00}$ values. ${ }^{72}$ A Franck-Condon line shape analysis $^{62,63}$ of the corrected PL spectra provided estimates of $\nu_{\mathrm{B}}$ and $v_{\mathrm{HB}}$ that were utilized in this calculation, thus qualitatively predicting the photoacid and photobase behavior, with quantitative values for the mcb containing compounds that were only $0.15 \mathrm{pK}_{\mathrm{a}}$ units different from those determined from spectral modeling of the PL titration data.

The $\mathrm{pH}$ induced spectral changes are understood based on the nature of the emitting state and the inductive influence of the ionizable groups as was discussed above. Recall that the bathochromic shift of the photoacids results from the inductive influence of acid-base chemistry on the $\mathrm{Ru}^{\mathrm{III} / \mathrm{II}}$ reduction potential. Consistent with this model was the fact that the presence of two carboxylic acid groups in $\left[\mathrm{Ru}^{\mathrm{II}}(\mathrm{btfmb})_{2}(\mathrm{dcb})\right]^{2+}$ resulted in about twice the $\Delta \mathrm{p} K_{\mathrm{a}}$ values as that measured for the mcb analogue. Compounds with additional carboxylic acid groups, such as $\left[\mathrm{Ru}^{\mathrm{II}}(\mathrm{btfmb})(\mathrm{dcb})_{2}\right]^{2+}$ would be expected to give even larger blue shifts in the PL spectra after excited state proton transfer. Similar behavior might have been expected for $4,4^{\prime}$ $(\mathrm{Cl})_{2}-2,2^{\prime}$-bipyridine compounds that also possess low-lying $\pi^{*}$ orbitals, however no significant spectral shifts were observed and protonation led to an unexpected decrease in PL intensity suggesting some alternative photochemistry. ${ }^{40}$ The bathochromic shift expected for photobases was observed for the dtb and bpy compounds reported here and for a much larger number of previously reported $\mathrm{dcb}$ containing transition metal compounds. ${ }^{1,2,27,29-34,40,48,96}$

Kinetics. When excited states localized on the dcb or mcb ligands were photogenerated at $\mathrm{pH}$ values where acid-base equilibria was relevant, time dependent PL spectral shifts were observed indicating that acid-base chemistry was occurring on the nanosecond time scale. In contrast, no spectral shifts were observed for the btfmb containing compounds, consistent with a more rapid establishment of the excited state equilibrium. These observations provide rough estimates of the rate constants for excited state proton transfer. More precise values have previously been abstracted from PL decays monitored at single observation 
Table 6. Kinetic Parameters Abstracted from the Coupled Systems Model of the Experimental Data

$\begin{array}{ccccccc}\text { compd } & \mathrm{pH}^{a} & k_{1}\left(\mathrm{~s}^{-1}\right) & k_{2}\left(\mathrm{~s}^{-1}\right) & k_{12}\left(\mathrm{M}^{-1} \mathrm{~s}^{-1}\right) & k_{21}\left(\mathrm{~s}^{-1}\right) & K_{\mathrm{eq}} \\ {\left[\mathrm{Ru}(\mathrm{bpy})_{2}(\mathrm{mcb})\right]^{2+}} & 2.7 & 2.94 \times 10^{6} & 3.71 \times 10^{6} & 7.83 \times 10^{9} & 7.01 \times 10^{6} & 1.05 \times 10^{3} \\ {\left[\mathrm{Ru}(\mathrm{dtb})_{2}(\mathrm{mcb})\right]^{2+}} & 3.0 & 4.72 \times 10^{6} & 6.54 \times 10^{6} & 1.96 \times 10^{10} & 5.96 \times 10^{6} & 3.15 \times 10^{3}\end{array}$

${ }^{a_{\mathrm{T}}} \mathrm{Th} \mathrm{pH}$ at which the time-resolved photoluminescence decays were acquired.
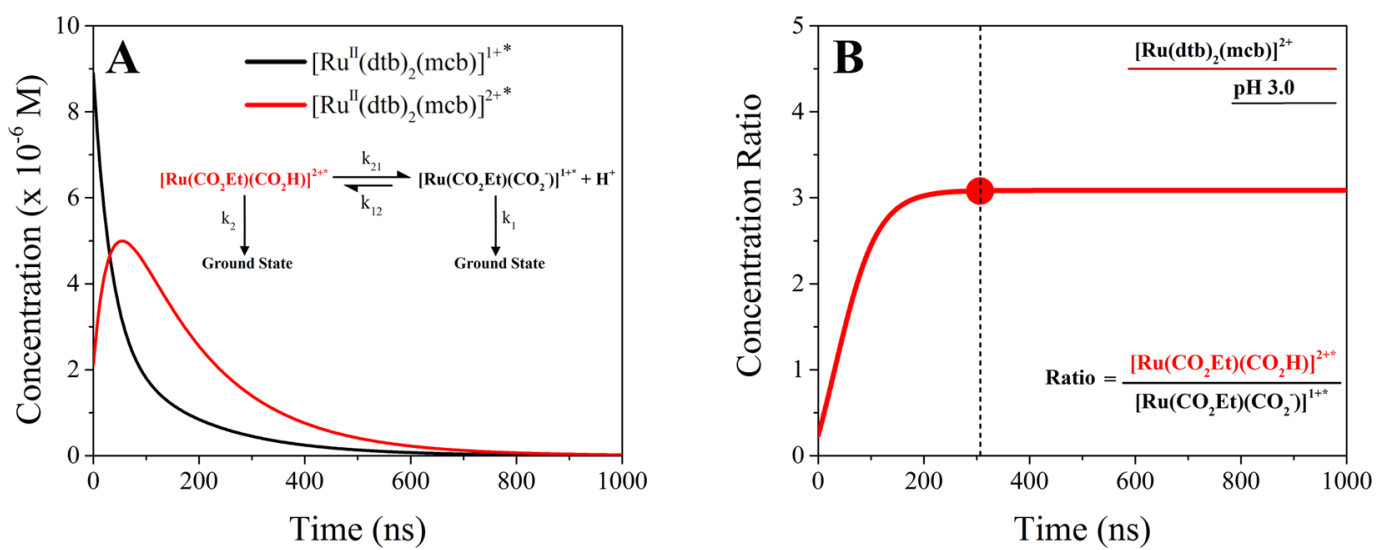

Figure 10. (A) Excited state concentrations of the deprotonated $\left[\mathrm{Ru}(\mathrm{dtb})_{2}(\mathrm{mcb})\right]^{+*}$, black, and protonated $\left[\mathrm{Ru}(\mathrm{dtb})_{2}(\mathrm{mcb})\right]^{2+*}, \mathrm{red}, \mathrm{compounds}$ abstracted from kinetic analysis of the bi-exponential PL decays measured after pulsed light excitation of $\left[\mathrm{Ru}(\mathrm{dtb})_{2}(\mathrm{mcb})\right]^{2+}$. (B) The given excited state concentration ratio as a function of time; the dotted line near $300 \mathrm{~ns}$ indicates the time when a steady state quasi-equilibrium was achieved.

wavelengths from organic singlet states. ${ }^{14,97}$ Here we apply this analysis to inorganic compounds for the first time and restrict such analysis to the photobasic mcb compounds that were not complicated by a second excited state equilibrium, Figure 9.

The square scheme shown in Figure 9 has been widely used to understand the acid-base chemistry of organic excited states, ${ }^{14,22,25,97}$ and is also relevant to other excited state equilibrium processes such as excimer formation. The rate equations that describe the single acid-base equilibrium are given in eqs 9 and 10.

$$
\begin{aligned}
& \frac{\mathrm{d}\left[A^{*}\right]}{\mathrm{d} t}=-\left(k_{2}+k_{21}\right)\left[A^{*}\right]+k_{12}\left[B^{*}\right] \\
& \frac{\mathrm{d}\left[B^{*}\right]}{\mathrm{d} t}=+k_{21}\left[A^{*}\right]-\left(k_{1}+k_{12}\right)\left[B^{*}\right]
\end{aligned}
$$

For simplification, $\left[A^{*}\right]$ and $\left[B^{*}\right]$ refer to the concentrations of the excited protonated acid, $\left[\mathrm{Ru}\left(\mathrm{CO}_{2} \mathrm{Et}\right)\left(\mathrm{CO}_{2} \mathrm{H}\right)\right]^{2+*}$, and the conjugated base, $\left[\mathrm{Ru}\left(\mathrm{CO}_{2} \mathrm{Et}\right)\left(\mathrm{CO}_{2}^{-}\right)\right]^{1+*}$, respectively. The differential equations were solved for the general case where the initial boundary condition accounts for the excitation of both $\left[A^{*}\right](t=0 \mathrm{~s})=A_{0}$ and $\left[\mathrm{B}^{*}\right](t=0 \mathrm{~s})=B_{0}$. For detailed description of the solutions to these coupled differential equations the authors recommend the work of Brand, ${ }^{14,97}$ or the text by Demas, ${ }^{25}$ that requires knowledge of the excited state concentrations $\left[A^{*}\right]$ and $\left[B^{*}\right]$. Because PL intensities do not report on concentrations, it was necessary to introduce the constants $a$ and $b$ for appropriate conversion. As the measured PL spectra of the acid and conjugate bases overlap in the amplitude at each observation wavelength, $a(\lambda)$ and $b(\lambda)$ were analyzed, eq 11 .

$$
\operatorname{PLI}(\lambda, t)=a(\lambda)\left[A^{*}\right](t)+b(\lambda)\left[B^{*}\right](t)
$$

At $\mathrm{pH}$ values were the excited state equilibrium was operative, biexponential kinetics were observed for the photobasic compounds under study consistent with eqs 9 and 10 . Biexponential relaxation behavior for $\mathrm{Ru}$ polypyridyl excited states were reported in the past, ${ }^{31,39}$ although their importance remained unclear. The kinetic data reported here could not be modeled by a weighted sum of the protonated and deprotonated lifetimes of the compound as might naively have been expected. Instead, the two lifetimes abstracted from a biexponential analysis represent the dynamics of the entire system as was first shown in 1972..$^{14,25,97}$ The lifetimes $\tau_{1}$ and $\tau_{2}$ abstracted from biexponential fits are functions of all the rate constants, $k_{1}, k_{2}, k_{12}$, and $k_{21}$ present in the equilibrium system. ${ }^{14,22,25,97}$ Fortunately, the relevant differential equations have previously been solved and allow for a complete system analysis. ${ }^{14,25,97}$

The unimolecular rate constants for deprotonation of $\left[\mathrm{Ru}(\mathrm{dtb})_{2}(\mathrm{mcb})\right]^{2+*}$ and $\left[\mathrm{Ru}(\mathrm{bpy})_{2}(\mathrm{mcb})\right]^{2+*}$ of $k_{21}=(5-7)$ $\times 10^{6} \mathrm{~s}^{-1}$ were at least an order of magnitude smaller than those previously reported for excited phenols and carboxylic acid compounds. ${ }^{69}$ The time required to establish steady state concentrations, that is, "quasi-equilibrium", was calculated with the abstracted rate constants in Table 6. Representative data of the time dependent concentrations present after pulsed laser excitation of $\left[\mathrm{Ru}(\mathrm{dtb})_{2}(\mathrm{mcb})\right]^{2+}$ are shown in Figure 10. About $300 \mathrm{~ns}$ were required for establishment of the quasi-equilibrium and a similar time scale was observed for $\left[\mathrm{Ru}(\mathrm{bpy})_{2}(\mathrm{mcb})\right]^{2+*}$. In contrast, the excited-state acid-base equilibrium was established on a sub-300 ps time scale for the btfmb compounds. A plausible explanation for the very disparate time scales for excited state equilibration is that the orientation of the excitedstate dipole relative to the ligand that undergoes acid-base chemistry directly influences proton transfer dynamics. When the excited-state dipole was oriented toward the mcb ligand, Coulombic interactions with the proton slowed transfer relative to the situation where the dipole was oriented away from the ionizable ligand. This kinetic data provided $\mathrm{p} K_{\mathrm{a}}{ }^{*}$ values that were within $0.1 \mathrm{pK}_{\mathrm{a}}$ units of those abstracted from steady state PL titrations. Indeed self-consistent $\mathrm{pK}_{\mathrm{a}}{ }^{*}$ values obtained from PL titrations, Förster cycles, and this kinetic analysis.

The orientation of the excited state dipole relative to the $\mathrm{dcb}$ ligand is also relevant to their use in dye-sensitized solar cells 
(DSSCs), ${ }^{50-52}$ where it is generally believed that excited state injection is optimal when the charge transfer dipole is oriented toward the semiconductor surface. ${ }^{98}$ Since the 2010 report of a $2.4 \%$ efficient aqueous DSSC, ${ }^{99}$ there has been renewed interest in water-based electrolytes for DSSCs and a review article on this subject has recently appeared. ${ }^{100}$ The ground state acid-base chemistry reported here can impact the surface stability of dye molecules, protons are expected to compete with $\mathrm{TiO}_{2}$ surface states that comprise the carboxylate linkages under $\mathrm{pH}$ conditions near and below the ground state $\mathrm{p} K_{\mathrm{a}}$ values. Due to the Nernstian shift of the band edge positions with $\mathrm{pH}$, acidic conditions favor excited state injection. ${ }^{51}$ In addition, quartz crystal microbalance studies have shown that electron injection into $\mathrm{TiO}_{2}$ is accompanied by charge-compensating uptake of a proton. ${ }^{101}$ It is interesting to consider whether an excited dye molecule that transfers both an electron and a proton to the semiconductor surface would be advantageous for DSSCs since such charge neutral reactions are expected to have small reorganization energies. With regard to this study, the $[\mathrm{Ru}-$ $\left.(\mathrm{dtb})_{2}(\mathrm{dcb})\right]^{2+}$ or $\left[\mathrm{Ru}(\mathrm{bpy})_{2}(\mathrm{dcb})\right]^{2+}$ have optimal dipole alignment for excited state injection, but their photobasic character would be undesirable for proton transfer to the semiconductor. In contrast, the photoacidic behavior of $\left[\mathrm{Ru}(\mathrm{btfmb})_{2}(\mathrm{dcb})\right]^{2+*}$ is ideal for proton transfer, but with a nonoptimal dipole orientation for interfacial electron transfer. New transition metal compounds that vectorially transfer both protons and electrons are hence of interest for applications in DSSCs and other artificial photosynthetic devices. $10,17-19,102$

\section{CONCLUSIONS}

Ruthenium polypyridyl compounds were made photobasic or photoacidic through control of the orientation of the charge transfer excited state relative to the ligand with conjugated carboxylic acid groups. Excited states localized on the ligand with the carboxylic acid group were photobases while those localized on an alternative ligand were photoacids. This previously unrecognized behavior provides new opportunities for fundamental and practical applications of these and related transition metal compounds. Studies of how specific buffers influence the excited state proton transfer reactions would be particularly useful for elucidating their role in light driven water splitting and solar fuels production. The $\mathrm{pH}$ range and magnitude of $\Delta \mathrm{p} K_{\mathrm{a}}$ could be further tuned by the incorporation of alternative functional groups, such as amines or phenols. The finding that the excited state need not be localized on the ligand undergoing acid base chemistry implies that a single transition metal compound with three (or more) different acid-base groups could be synthesized and would be responsive at multiple $\mathrm{pH}$ values in a predictable fashion.

\section{ASSOCIATED CONTENT}

\section{S Supporting Information}

The Supporting Information is available free of charge on the ACS Publications website at DOI: 10.1021/jacs.6b00454.

Absorption and PL spectra of the de-, mono-, and diprotonated forms of the compounds; plot of the nonradiative rate constant versus the ground-excited state energy gap; absorption and PL titrations; tabulated values of the Franck-Condon line shape analysis of the corrected PL spectra; and tabulated $\mathrm{p} K_{\mathrm{a}}^{*}$ values (PDF) Crystallographic data (CIF)

\section{AUTHOR INFORMATION}

\section{Corresponding Author}

*gjmeyer@email.unc.edu

\section{Notes}

The authors declare no competing financial interest.

\section{ACKNOWLEDGMENTS}

The research was part of the UNC EFRC: Center for Solar Fuels, an Energy Frontier Research Center funded by the U.S. Department of Energy (DOE), Office of Science, Basic Energy Sciences BES, under Award DE-SC0001011. R.M.O. would also like to thank the National Science Foundation for an individual Graduate Research Fellowship under Grant No. DGE-1232825. We thank John Papanikolas for use of a streak-camera and Ludwig Brand for stimulating discussions.

\section{REFERENCES}

(1) Vos, J. G. Polyhedron 1992, 11, 2285

(2) Hicks, C.; Ye, G.; Levi, C.; Gonzales, M.; Rutenburg, I.; Fan, J.; Helmy, R.; Kassis, A.; Gafney, H. D. Coord. Chem. Rev. 2001, 211, 207.

(3) Greiner, G.; Maier, I. J. Chem. Soc., Perkin Trans. 2 2002, 1005.

(4) Whitaker, J. E.; Haugland, R. P.; Prendergast, F. G. Anal. Biochem. 1991, 194, 330.

(5) Lakowicz, J. R. In Principles of Fluorescence Spectroscopy; Lakowicz, J. R., Ed.; Springer: New York, 2006; p 623.

(6) Crivello, J. V.; Dietliker, K.; Bradley, G. Photoinitiators for Free Radical Cationic \& Anionic Photopolymerisation; Wiley: New York, 1999; Vol. 3.

(7) Zhou, W.; Kuebler, S. M.; Braun, K. L.; Yu, T.; Cammack, J. K.; Ober, C. K.; Perry, J. W.; Marder, S. R. Science 2002, 296, 1106.

(8) Nakashima, T.; Tsuchie, K.; Kanazawa, R.; Li, R.; Iijima, S.; Galangau, O.; Nakagawa, H.; Mutoh, K.; Kobayashi, Y.; Abe, J.; Kawai, T. J. Am. Chem. Soc. 2015, 137, 7023.

(9) Serafinowski, P. J.; Garland, P. B. J. Am. Chem. Soc. 2003, 125, 962.

(10) Dempsey, J. L.; Winkler, J. R.; Gray, H. B. J. Am. Chem. Soc. 2010, 132,16774

(11) Murtaza, Z.; Chang, Q.; Rao, G.; Lin, H.; Lakowicz, J. R. Anal. Biochem. 1997, 247, 216.

(12) Bowie, L. J.; Irwin, R.; Loken, M.; DeLuca, M.; Brand, L. Biochemistry 1973, 12, 1852.

(13) Laws, W. R.; Posner, G. H.; Brand, L. Arch. Biochem. Biophys. 1979, 193, 88

(14) Loken, M. R.; Hayes, J. W.; Gohlke, J. R.; Brand, L. Biochemistry 1972, 11, 4779 .

(15) Abeyrathna, N.; Liao, Y. J. Am. Chem. Soc. 2015, 137, 11282.

(16) Tatum, L. A.; Foy, J. T.; Aprahamian, I. J. Am. Chem. Soc. 2014, 136, 17438.

(17) Zhou, D.; Khatmullin, R.; Walpita, J.; Miller, N. A.; Luk, H. L.; Vyas, S.; Hadad, C. M.; Glusac, K. D. J. Am. Chem. Soc. 2012, 134, 11301.

(18) Eisenhart, T. T.; Dempsey, J. L. J. Am. Chem. Soc. 2014, 136, 12221.

(19) Tolbert, L. M.; Haubrich, J. E. J. Am. Chem. Soc. 1994, 116, 10593.

(20) Huynh, M. H. V.; Meyer, T. J. Chem. Rev. 2007, 107, 5004.

(21) Wenger, O. S. Acc. Chem. Res. 2013, 46, 1517.

(22) Ireland, J. F.; Wyatt, P. A. H. In Advances in Physical Organic Chemistry; Gold, V., Ed.; Academic Press: New York, 1976; Vol. 12, p 131.

(23) Shizuka, H. Acc. Chem. Res. 1985, 18, 141.

(24) Tolbert, L. M.; Solntsev, K. M. Acc. Chem. Res. 2002, 35, 19.

(25) Demas, J. N. In Excited State Lifetime Measurements; Demas, J. N., Ed.; Academic Press: New York, 1983; p 43.

(26) Peterson, S. H.; Demas, J. N. J. Am. Chem. Soc. 1976, 98, 7880.

(27) Giordano, P. J.; Bock, C. R.; Wrighton, M. S.; Interrante, L. V.; Williams, R. F. X. J. Am. Chem. Soc. 1977, 99, 3187.

(28) Giordano, P. J.; Bock, C. R.; Wrighton, M. S. J. Am. Chem. Soc. 1978, 100, 6960. 
(29) Xie, P.-H.; Hou, Y.-J.; Zhang, B.-W.; Cao, Y. J. Photochem. Photobiol., A 1999, 122, 169.

(30) Xie, P.-H.; Hou, Y.-J.; Zhang, B.-W.; Cao, Y.; Wu, F.; Tian, W.-J.; Shen, J.-C. J. Chem. Soc., Dalton Trans. 1999, 4217.

(31) Nazeeruddin, M. K.; Kalyanasundaram, K. Inorg. Chem. 1989, 28, 4251.

(32) Lay, P. A.; Sasse, W. H. F. Inorg. Chem. 1984, 23, 4123.

(33) Shimidzu, T.; Iyoda, T.; Izaki, K. J. Phys. Chem. 1985, 89, 642.

(34) Higgins, B.; DeGraff, B. A.; Demas, J. N. Inorg. Chem. 2005, 44, 6662 .

(35) Dixon, E. N.; Snow, M. Z.; Bon, J. L.; Whitehurst, A. M.; DeGraff,

B. A.; Trindle, C.; Demas, J. N. Inorg. Chem. 2012, 51, 3355.

(36) Cargill Thompson, A. M. W.; Smailes, M. C. C.; Jeffery, J. C.; Ward, M. D. J. Chem. Soc., Dalton Trans. 1997, 737.

(37) Kirsch-De Mesmaeker, A.; Jacquet, L.; Nasielski, J. Inorg. Chem. 1988, 27, 4451.

(38) Peterson, S. H.; Demas, J. N. J. Am. Chem. Soc. 1979, 101, 6571.

(39) Buchanan, B. E.; Vos, J. G.; Kaneko, M.; van der Putten, W. J. M.; Kelly, J. M.; Hage, R.; de Graaff, R. A. G.; Prins, R.; Haasnoot, J. G.; Reedijk, J. J. Chem. Soc., Dalton Trans. 1990, 2425.

(40) Su, C.-H.; Chen, H.-Y.; Tsai, K. Y.-D.; Chang, I. J. J. Phys. Chem. B 2007, 111, 6857.

(41) Browne, W. R.; O’Connor, C. M.; Hughes, H. P.; Hage, R.; Walter, O.; Doering, M.; Gallagher, J. F.; Vos, J. G. J. Chem. Soc., Dalton Trans. 2002, 4048.

(42) Cummings, S. D.; Eisenberg, R. Inorg. Chem. 1995, 34, 3396.

(43) Das, S.; Saha, D.; Mardanya, S.; Baitalik, S. Dalton transactions 2012, 41, 12296.

(44) Leasure, R. M.; Sacksteder, L.; Nesselrodt, D.; Reitz, G. A.; Demas, J. N.; DeGraff, B. A. Inorg. Chem. 1991, 30, 3722.

(45) Leavens, B. H.; Trindle, C.; Sabat, M.; Altun, Z.; Demas, J.; DeGraff, B. A. J. Fluoresc. 2012, 22, 163.

(46) Maity, D.; Bhaumik, C.; Karmakar, S.; Baitalik, S. Inorg. Chem. 2013, 52, 7933.

(47) Maity, D.; Mardanya, S.; Karmakar, S.; Baitalik, S. Dalton transactions 2015, 44, 10048.

(48) Ferguson, J.; Mau, A. W. H.; Sasse, W. H. F. Chem. Phys. Lett. 1979, 68, 21.

(49) Mikšovská, J.; Larsen, R. W. Inorg. Chem. 2004, 43, 4051.

(50) Grätzel, M. J. Photochem. Photobiol., C 2003, 4, 145.

(51) Ardo, S.; Meyer, G. J. Chem. Soc. Rev. 2009, 38, 115.

(52) Hagfeldt, A.; Boschloo, G.; Sun, L.; Kloo, L.; Pettersson, H. Chem. Rev. 2010, 110, 6595.

(53) Adamson, K.; Dolan, C.; Moran, N.; Forster, R. J.; Keyes, T. E. Bioconjugate Chem. 2014, 25, 928.

(54) Al-Rawashdeh, N. A. F.; Chatterjee, S.; Krause, J. A.; Connick, W. B. Inorg. Chem. 2014, 53, 294.

(55) Gillaizeau-Gauthier, I.; Odobel, F.; Alebbi, M.; Argazzi, R.; Costa, E.; Bignozzi, C. A.; Qu, P.; Meyer, G. J. Inorg. Chem. 2001, 40, 6073.

(56) Swords, W. B.; Li, G.; Meyer, G. J. Inorg. Chem. 2015, 54, 4512.

(57) Benson, E. E.; Grice, K. A.; Smieja, J. M.; Kubiak, C. P. Polyhedron 2013, 58, 229.

(58) Furue, M.; Maruyama, K.; Oguni, T.; Naiki, M.; Kamachi, M. Inorg. Chem. 1992, 31, 3792.

(59) Crosby, G. A.; Demas, J. N. J. Phys. Chem. 1971, 75, 991.

(60) Ardo, S.; Sun, Y.; Staniszewski, A.; Castellano, F. N.; Meyer, G. J. J. Am. Chem. Soc. 2010, 132, 6696.

(61) Lee, E. C.; Kim, D.; Jurečka, P.; Tarakeshwar, P.; Hobza, P.; Kim, K. S. J. Phys. Chem. A 2007, 111, 3446.

(62) Johansson, P. G.; Zhang, Y.; Meyer, G. J.; Galoppini, E. Inorg. Chem. 2013, 52, 7947.

(63) Damrauer, N. H.; Boussie, T. R.; Devenney, M.; McCusker, J. K. J. Am. Chem. Soc. 1997, 119, 8253.

(64) Forster, L. S. Coord. Chem. Rev. 2006, 250, 2023.

(65) Yersin, H.; Gallhuber, E. J. Am. Chem. Soc. 1984, 106, 6582.

(66) Kovi, P. J.; Schulman, S. G. Anal. Chem. 1973, 45, 989.

(67) Marzzacco, C. J.; Deckey, G.; Halpern, A. M. J. Phys. Chem. 1982, 86, 4937.

(68) Watkins, A. R. J. Chem. Soc., Faraday Trans. 1 1972, 68, 28.
(69) Arnaut, L. G.; Formosinho, S. J. J. Photochem. Photobiol., A 1993, $75,1$.

(70) Caspar, J. V.; Meyer, T. J. J. Am. Chem. Soc. 1983, 105, 5583.

(71) Durham, B.; Caspar, J. V.; Nagle, J. K.; Meyer, T. J. J. Am. Chem. Soc. 1982, 104, 4803.

(72) Hager, G. D.; Crosby, G. A. J. Am. Chem. Soc. 1975, 97, 7031.

(73) Juris, A.; Balzani, Y.; Barigelletti, F.; Campagna, S.; Belser, P.; Von Zelewsky, A. Coord. Chem. Rev. 1988, 84, 85.

(74) Van Houten, J.; Watts, R. J. J. Am. Chem. Soc. 1976, 98, 4853.

(75) Bradley, P. G.; Kress, N.; Hornberger, B. A.; Dallinger, R. F.; Woodruff, W. H. J. Am. Chem. Soc. 1981, 103, 7441.

(76) Dallinger, R. F.; Woodruff, W. H. J. Am. Chem. Soc. 1979, 101, 4391.

(77) Schoonover, J. R.; Bignozzi, C. A.; Meyer, T. J. Coord. Chem. Rev. 1997, 165, 239.

(78) McClanahan, S. F.; Dallinger, R. F.; Holler, F. J.; Kincaid, J. R. J. Am. Chem. Soc. 1985, 107, 4853.

(79) Danzer, G. D.; Kincaid, J. R. J. Phys. Chem. 1990, 94, 3976.

(80) Mabrouk, P. A.; Wrighton, M. S. Inorg. Chem. 1986, 25, 526.

(81) Smothers, W. K.; Wrighton, M. S. J. Am. Chem. Soc. 1983, 105, 1067.

(82) Hansch, C.; Leo, A.; Taft, R. W. Chem. Rev. 1991, 91, 165.

(83) Lowry, T. H.; Richardson, K. S. Mechanism and Theory in Organic Chemistry, 3rd ed.; Benjamin-Cummings Publishing Company: San Francisco, 1997.

(84) Cole, T. W.; Mayers, C. J.; Stock, L. M. J. Am. Chem. Soc. 1974, 96, 4555.

(85) Caspar, J. V.; Meyer, T. J. Inorg. Chem. 1983, 22, 2444.

(86) Kober, E. M.; Caspar, J. V.; Lumpkin, R. S.; Meyer, T. J. J. Phys. Chem. 1986, 90, 3722.

(87) Bixon, M.; Jortner, J. J. Chem. Phys. 1968, 48, 715.

(88) Strouse, G. F.; Schoonover, J. R.; Duesing, R.; Boyde, S.; Jones, W. E., Jr.; Meyer, T. J. Inorg. Chem. 1995, 34, 473.

(89) Treadway, J. A.; Loeb, B.; Lopez, R.; Anderson, P. A.; Keene, F. R.; Meyer, T. J. Inorg. Chem. 1996, 35, 2242.

(90) Xie, P.-H.; Hou, Y.-J.; Zhang, B.-W.; Cao, Y.; Wu, F.; Tian, W.-J.; Shen, J.-C. J. Chem. Soc., Dalton Trans. 1999, 4217.

(91) Förster, T. Naturwissenschaften 1949, 36, 186.

(92) Weller, A. Z. Elektrochem. 1952, 56, 662.

(93) Weller, A. Z. Elektrochem. 1954, 58, 849.

(94) Förster, T. Z. Elektrochem. 1950, 54, 42.

(95) Förster, T. Z. Elektrochem. 1950, 54, 531.

(96) Zheng, G. Y.; Wang, Y.; Rillema, D. P. Inorg. Chem. 1996, 35, 7118.

(97) Laws, W. R.; Brand, L. J. Phys. Chem. 1979, 83, 795.

(98) Mathew, S.; Yella, A.; Gao, P.; Humphry-Baker, R.; CurchodBasile, F. E.; Ashari-Astani, N.; Tavernelli, I.; Rothlisberger, U.; NazeeruddinMd, K.; Grätzel, M. Nat. Chem. 2014, 6, 242.

(99) Law, C.; Pathirana, S. C.; Li, X.; Anderson, A. Y.; Barnes, P. R. F.; Listorti, A.; Ghaddar, T. H.; O'Regan, B. C. Adv. Mater. 2010, 22, 4505.

(100) Bella, F.; Gerbaldi, C.; Barolo, C.; Gratzel, M. Chem. Soc. Rev. 2015, 44, 3431.

(101) Lemon, B. I.; Hupp, J. T. J. Phys. Chem. 1996, 100, 14578.

(102) Valdez, C. N.; Schimpf, A. M.; Gamelin, D. R.; Mayer, J. M. J. Am. Chem. Soc. 2016, 138, 1377. 